\title{
Article \\ Defense Installation Energy Resilience for Changing Operational Requirements
}

\author{
Janice Mallery, Douglas L. Van Bossuyt*(D) and Anthony Pollman
}

check for updates

Citation: Mallery, J.; Van Bossuyt, D.L.; Pollman, A. Defense Installation Energy Resilience for Changing Operational Requirements. Designs 2022, 6, 28. https://doi.org/ $10.3390 /$ designs 6020028

Academic Editor: Mohammad Hassan Khooban

Received: 5 January 2022

Accepted: 28 February 2022

Published: 3 March 2022

Publisher's Note: MDPI stays neutral with regard to jurisdictional claims in published maps and institutional affiliations.

Copyright: (C) 2022 by the authors. Licensee MDPI, Basel, Switzerland. This article is an open access article distributed under the terms and conditions of the Creative Commons Attribution (CC BY) license (https:// creativecommons.org/licenses/by/ $4.0 /)$.

\author{
Department of Systems Engineering, Naval Postgraduate School, Monterey, CA 93940, USA; \\ janice.mallery@nps.edu (J.M.); agpollma@nps.edu (A.P.) \\ * Correspondence: douglas.vanbossuyt@nps.edu
}

\begin{abstract}
We propose a methodology to determine the impact of different potential mission scenarios upon energy resilience for mission-critical loads attached to a military base's microgrid infrastructure. The proposed methodology applies to any installation with changing operational states that has energy-resilience requirements. The proposed methodology may be used by energy managers to account for potential mission scenarios that a base may be part of, followed by assessing the microgrid energy resilience to supply the critical loads for said mission scenarios, especially where the external grid power may be unavailable and/or damage to microgrid components may be present. In the event a microgrid design is unable to provide sufficient electrical energy, distributed energy resources and energy storage systems including renewable energy resources may be added to improve energy resilience. A case study is conducted on a fictitious representative military base, microgrid design, and changing mission demands to demonstrate the application of the proposed methodology. This article contributes a methodology for energy managers to evaluate energy resilience using microgrids by accounting for potential mission scenarios, their energy requirements, resulting energy preparedness, and recommendations for improvement, as necessary.
\end{abstract}

Keywords: microgrid; resilience; mission engineering; systems engineering; energy storage

\section{Introduction}

The importance of electrical energy to successfully execute defense and national security missions is increasing. Modern militaries often require electronic equipment to complete their tasks. Lack of readily available power impacts mission readiness and effectiveness of militaries and other organizations entrusted with national security missions. In order to ensure that electrical energy is available, electricity supplies must be reliable, resilient, and secure. Of particular interest to this research is the resilience of electricity supplies used for national security missions.

10 U.S.C $\$ 101(\mathrm{e})(6)$ defines energy resilience as "the ability to avoid, prepare for, minimize, adapt to, and recover from anticipated and unanticipated energy disruptions to ensure energy availability and reliability sufficient to provide for ... mission essential requirements" ([1], (6)). Resilience for United States (US) military installations is defined in 10 U.S.C $\$ 101(\mathrm{e})(8)$ as "the capability of a military installation to avoid, prepare for, minimize the effect of, adapt to, and recover from extreme weather events ... [that] have the potential to adversely affect the military installation" ([1], (8)). Although US law focuses on the weather and the environment, we also include potential adversarial threats that disrupt energy supplies in our understanding of installation resilience.

Several recent publications focus on systems engineering approaches to improve energy resilience for national security installations [2-5]. However, most exigent work assumes a constant operational environment with predictable loads. Although most missions a facility may perform can be predicted months or years in advance and operational environments rarely change significantly, this is not always the case. For instance, a facility 
with a port may conduct nominal operations with ships coming and going on predictable schedules. However, a battle-damaged ship [6], or a ship that has suffered a significant collision [7] may drastically change the operating environment of the facility due to unplanned mission needs of stabilizing damaged vessels, treating wounded, housing additional personnel due to recovery efforts, and other activities. Such a rapid and unpredictable change in the operational environment of a facility can adversely impact the resilience of electrical energy sources due to insufficient preparation for load demand at the facility.

Many facilities involved with national security and defense have implemented microgrids to improve energy resilience. A microgrid is a system of system (SOS) consisting of interconnected loads and distributed energy resources (DERs) within an established electrical boundary specifically designed to operate in either a grid-connected or islanded mode [4]. Generally, national security installation microgrids are sized to protect critical loads, defined as those supporting safety, process reliability, and operational requirements [8]. Yet, critical loads for operational requirements are those which require continuous electrical power in the event of disruption [3].

In a scenario such as a ship coming into a port after sustaining significant damage, the critical loads of the facility increase to include both the day-to-day critical loads and the transitory critical loads created by the change in operational environment. Thus, sometimes facility electrical energy resilience can decrease if additional loads are required to be rapidly supported with little warning or time available for proper preparation.

Currently there exists little guidance on how to analyze a defense installation microgrid for energy resilience from the perspective of changing operational requirements. In some cases, we have observed microgrids being overbuilt by a factor of ten or more versus the most conservative designs from a resilience perspective because at least in part energy managers do not have analysis methods available to determine what potential loads may need to be supported in the future. In other instances, we have observed microgrids operating at capacity under nominal conditions and with minimal provisions to support critical loads during a failure scenario or with changing operational requirements. In such cases, the response is often to enter a multi-year contracting process to upgrade a microgrid to support a specific new load but not address larger resilience concerns.

\section{Specific Contribution}

This paper contributes to the literature a system-engineering method for microgrid resilience analysis that specifically accounts for potential mission operations, their energy requirements, and verifies the microgrid design adequacy for system energy preparedness. A mission engineering perspective is used to ensure changing operational load demands are met. The method is implemented in a modeling and simulation tool for verification of microgrid resilience to damaging events. The method is iterative and can be used to develop design improvements. This method enables energy managers to ensure their microgrid systems are prepared to provide electrical power for new potential critical loads for foreseen mission scenarios.

\section{Background and Literature Review}

\subsection{Government Requirements}

Each nation or industry may have their own requirements or regulations to meet energy security objectives, which should be considered during energy-resilience analysis. For example, the US Department of Defense (DOD) requires facilities to collaborate with tenants, mission owners, and operators to ensure power is continuously available for critical operations [9]. Collaboration is important as the facility energy manager may not know the specifics of what each mission entails. Identification of what missions are considered critical may not be readily apparent which furthers the importance of collaboration and discussion with stakeholders [10]. The priorities for energy supply during failure events need to be established based upon the critical missions a facility performs [11]. 


\subsection{Energy Resilience}

A continuous power supply is necessary for missions with operations that depend on electrical systems. Common definitions in the literature for resilience include withstanding a hazard, rapidly responding to and recovering from damage, and adapting a system for future preparedness [12]. A system may seek to reduce failure probabilities, reduce the consequences when a failure occurs, and/or reduce the recovery rate to restore the system to normal operating parameters to improve resilience [13]. Many resilient electrical systems minimize the damage that occurs by decreasing vulnerability to weather and adversarial attacks while enabling quick recovery. Figure 1 depicts the general definition of resilience and its stages [13].

\section{System Resilience Curve}

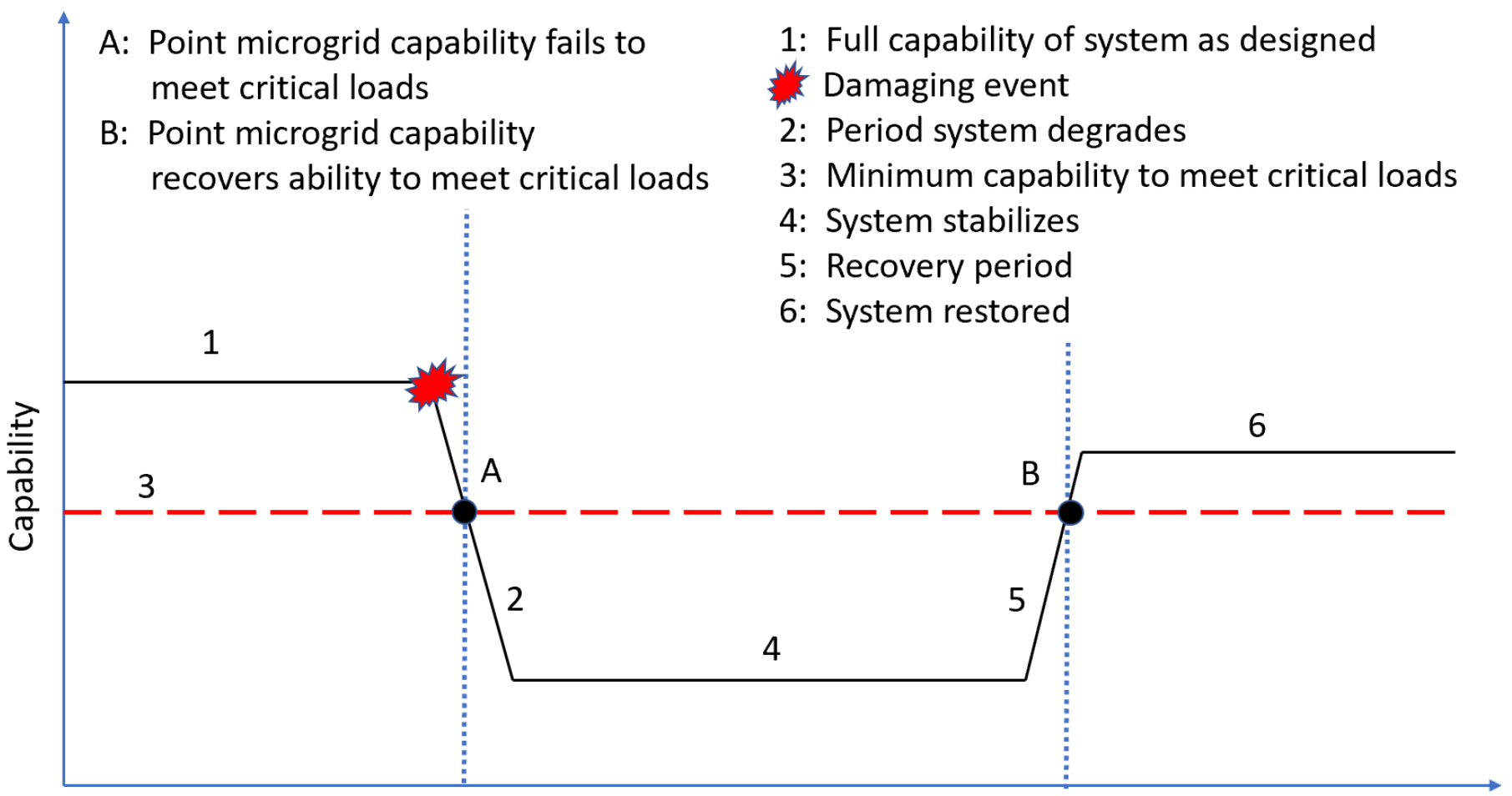

Time

Figure 1. System Resilience Curve. This image describes the resilience definition of the system based upon the capability before and after a damaging event, as well as the time the system is below the minimum capability to meet critical load demands [13].

The duration of installation resilience requirements varies per US military branch. The US Navy generally requires 7 days of autonomy while up to 14 days of autonomy can be required by the US Army and Marines based upon the mission contingency timelines [3,10]. We use 14 days of autonomy in the case study of this article. 


\subsection{Microgrids}

Many utility companies build and operate their electrical infrastructure based upon average historical conditions. This can result in any abnormal weather or environmental events or conditions causing service interruptions to the customer [14]. Although civilian customers may be unhappy with the inconvenience of power interruptions, the potential consequences of a civilian power outage are relatively low compared to those of defense installation outages. Due to national security requirements for resilient electrical power supply on defense installations, consumer interest in locally resilient power supply, and renewable energy goals, there have been many recent publications demonstrating microgrids as a successful and practical electrical resilience measure [3,12,15-25].

The Department of Energy (DOE) definition of a microgrid is "a group of interconnected loads and DERs within clearly defined electrical boundaries that acts as a single controllable entity with respect to the grid" [16]. Other definitions exist, but similarities include the power grid being independent and confined, with the ability to connect to the utility grid. When the microgrid is in islanded mode, the system is not connected to a utility grid and only the DERs and stored energy are used to supply power to the loads $[15,26]$. The components of a microgrid include the power generation sources, electrical loads, energy storage, and interfaces [15]. Studies have verified that microgrids, when well designed, increase energy resilience for a local area as an independent source of power when the city grid is interrupted $[12,14,15,27]$. When a weather-related anomaly or energy disruption to the utility grid occurs, a microgrid can use a high speed switch to transition from grid-connected mode to islanded mode with minimal interruptions [27,28], assuming the microgrid itself is not degraded or damaged by the event.

The successful implementation of microgrids for defense installations requires cooperation with local utilities [28]; an understanding of the loads that must be served to perform mission-critical functions [29]; and a design that supports differing operational requirements, climate, and geography for the specific location-in other words, one microgrid size does not fit all [10,30]. Examples of successful microgrid installation for DOD facilities include Naval Base Guam Telecommunications Site (NBGTS) in Finegaya, Guam, and Marine Corps Air and Ground Combat Center (MCAGCC) in Twentynine Palms, CA [29].

DOD facilities with existing microgrid installations have variability in facility load estimation as demonstrated by comparing the installed microgrid capacity with the specific facility energy consumption shown in Table 1. It is important to note that the energy consumption listed in the table is historical data that encompasses all types of energy consumption for the specific area in fiscal year (FY) 2019, and is not limited to only critical loads. Table 1 only displays historical data over a single year, which limits the location's representation of energy consumption in variable operational conditions. However, the size comparison in Table 1 makes for an interesting observation in scale difference between total energy consumed and the size of the microgrid that was installed. The installed microgrid capacity for Marine Corps Air Station (MCAS) Yuma, which has all of its power generated on-site [31], and Pacific Missile Range Facility (PMRF) Barking Sands, which cooperated with Kauai Island Utility for infrastructure on installation property [28,32], are examples of overestimation to ensure supportability while Naval Submarine Base New London appears to be equipped to only support the critical loads at a quarter of the total location's historical power usage in FY 2019. The Miramar microgrid was designed to potentially power the entire installation for full facility capability at all times [33], not being constrained to only critical load capability. Miramar and Twentynine Palms are grid-connected microgrids [31]. 
Table 1. Example DOD Microgrid Capacity and Facility Historical Energy Usage. This table displays currently installed military microgrids, their generation capacity, and how they compare to the total reported energy consumption at their respective locations. This comparison is limited to only one year's energy consumption data.

\begin{tabular}{|c|c|c|c|}
\hline Facility & Microgrid Capacity & $\begin{array}{c}\text { FY19 Energy } \\
\text { Consumption [29] }\end{array}$ & Comparison \\
\hline $\begin{array}{l}\text { Naval Submarine Base New } \\
\text { London }\end{array}$ & 7.4 MW fuel cell and microgrid $[32,34]$ & $28.2 \mathrm{MW}$ & $\begin{array}{l}\text { Approximately a quarter of } \\
\text { resilience power generated that } \\
\text { is demanded by the } \\
\text { entire facility }\end{array}$ \\
\hline $\begin{array}{l}\text { Marine Corps Air Station } \\
\text { (MCAS) Yuma }\end{array}$ & Ten 2.5 MW diesel generators [28] & $7.9 \mathrm{MW}$ & $\begin{array}{l}3.2 \text { times the power generation } \\
\text { capable as being demanded }\end{array}$ \\
\hline $\begin{array}{l}\text { Pacific Missile Range Facility } \\
\text { (PMRF) Barking Sands }\end{array}$ & $\begin{array}{c}\text { 14 MW AC plant including } 19.3 \mathrm{MW} \\
\text { DC solar PV and } 70 \mathrm{MWh} \text { battery } \\
\text { storage }[28,32]\end{array}$ & $2.9 \mathrm{MW}$ & $\begin{array}{l}6.6 \text { times the power generation } \\
\text { capable as being demanded }\end{array}$ \\
\hline MCAS Miramar & $\begin{array}{l}4 \mathrm{MW} \text { diesel generator, } 3 \mathrm{MW} \text { natural } \\
\text { gas generator, landfill gas and solar } \\
\text { photovoltaic power for a total of } 11.2 \\
\text { MW on-site power } \\
\text { generation }[29,31,33]\end{array}$ & $10.3 \mathrm{MW}$ & Approximately Equal \\
\hline $\begin{array}{l}\text { MCAGCC Twentynine } \\
\text { Palms }\end{array}$ & $\begin{array}{l}10 \mathrm{MW} \text { combined power generation } \\
\text { microgrid, [35] two } 16 \mathrm{MW} \text { combined } \\
\text { heat and power plants, chilled water } \\
\text { plants, } 5 \mathrm{MW} \text { PV [31] }\end{array}$ & 41.4 MW & Approximately Equal \\
\hline
\end{tabular}

\subsubsection{Distributed Energy Resources}

Microgrids may include renewable energy resources [12,36], which may increase resilience by withstanding disruptions due to fuel supply disruptions such as the 2021 Colonial Pipeline cyberattack which crippled fuel deliveries across its 5500-mile length along the United States east coast $[37,38]$. The literature includes methods for microgrid design to consider resilience as well as capacity, cost, reliability and sustainability with diesel generators, photovoltaic (PV) sources, battery energy storage system (BESS), and energy management system (EMS) components [5,39]. Other options for DER exist, but application of wind turbines, hydropower, compressed air storage and others may not be feasible for all locations [40].

\subsubsection{Energy Storage Systems}

An energy storage system (ESS) is often found as a component in a microgrid [21] and is an effective method for improving energy resilience as a backup energy source to mitigate unexpected power loss or a shortage of available grid-supplied energy to meet peak demands [40,41]. There are multiple types of ESS (e.g., batteries, pumped hydro energy storage, compressed air, flywheels, and fuel cells) with different energy storage capacities, costs, and applications [40]. An ESS enhances energy resilience by ensuring electrical equipment will still run in the event that microgrid power generation is lost or lacking (e.g., during the night for PV-equipped microgrids, while waiting for more fuel to be delivered to power diesel generators, repairing downed powerlines, etc.), assuming the ESS capacity is sufficient to support loads through repairs and restoration of service [42]. In the case of extended repairs, an ESS can allow time for operators to properly shut down equipment. ESS have limitations to their use based in part upon charging/discharging rates, safety, reliability, size, cost, and life-cycle management requirements [43]. Despite potential ESS limitations, microgrids equipped with PV generation and BESS, it is possible to increase electrical power resilience with better outcomes than using a backup diesel generator [44]. 


\subsubsection{Load Prioritization}

When there is insufficient power to meet all loads, many microgrids begin to shed lower priority loads [8]. However, in some situations a microgrid may not be configured to load shed and instead may shut down entirely to protect DERs and BESSs. Individual loads have different levels of importance associated with the mission impact of loads not being served. Nonessential loads which do not adversely affect mission operations or safety if not provided power are a low priority to service during a situation where there is insufficient power available to serve all loads. Conversely, mission-critical loads cannot be shed without risk to mission accomplishment and/or personnel and equipment safety [45].

Loads need to be prioritized against one another so that nonessential loads are shed first. This will prevent mission-critical loads from being shed or interrupted. There are multiple methods an energy manager can use to establish load prioritization. In almost all cases, communication and input from all affected organizations and stakeholders is required to identify critical loads [9]. In one instance, a case study conducted for Fort Bragg resulted in a year-long process to identify mission-critical facilities with results classified into four categories: life, health and safety; command and control; deployment; and life support [10]. Prioritization of loads then occurred within each of the four categories.

On a US naval vessel, there are three load shed categories (non-vital, semi-vital, and vital) that also prioritize load shedding. In the event the ship's electrical system fails to supply all loads demanded upon it, non-vital loads are shed first because the loss of these loads is not anticipated to adversely affect the operations of the ship or safety of the crew [45]. Semi-vital loads are considered important to ship operations but may be dropped to prevent damage to the ship's electrical system or complete electrical failure [45]. Vital loads are considered nonsheddable, as they affect the safety of the crew, or the ship [45]. Removing power from vital loads may result in personnel death or equipment destruction.

\subsubsection{Measures of Energy Resilience}

There are many ways to measure and define electrical grid resilience such as: the total degradation of service after an event; the time spent taking recovery actions; or the rate at which service is recovered [46]. A variety of tools and methods have been developed in the literature to study microgrid or energy resilience [2-4,10,47-50]. For instance, the Energyresilience Analysis (ERA) Tool [10] assesses energy resilience by comparing life-cycle costs related to system availability and reliability to assist decision makers with choosing alternative energy designs [10]. In some cases, the resilience measures are not quantitative but instead are qualitative and based in part on expert opinion using a scorecard to grade reliability, resilience, and efficiency of energy security and readiness [10]. Some methods use Mission Dependency Index (MDI) as a ranking scale for the importance of specific missions and is commonly used for defense and government facilities [2-4,47-50]. The expected electrical disruption impact (EEDMI) uses MDI as part of measuring military microgrid resilience [3], and further assigns probabilities to specific threat scenarios and their impact to critical loads if power is not received. Some have argued that MDI is oversimplified [47]; however, MDI remains in use throughout the military and in many other government agencies.

\subsection{Mission Engineering}

Mission engineering is a method of holistically evaluating a system or SOS to ensure a mission is executed successfully. This contrasts with engineering discipline practices of ensuring each individual part of a system works while sometimes losing focus on the overall system and mission intent. Mission engineering is formally defined as the application of SOS engineering with deliberate planning, analyzing, and integration of operational system capabilities to ensure achieving desired mission effects [51-55]. A mission differs from operations in that a mission is an assigned actionable task with a designated purpose [52] while operations are used to accomplish missions [51]. Mission engineering can be used to identify new technologies that are needed to achieve desired mission outcomes which then 
may be used in system development and acquisition to close identified mission capability gaps [52].

Mission Engineering has been used by National Aeronautics and Space Administration (NASA) to improve assurance of space launch mission achievement, and by government acquisitions processes to ensure individual engineering efforts satisfy mission support [54]. A method for mission engineering and analysis (MEA) was developed by [51] and a simulated application of mission engineering was conducted by [55] which included analytic support tools. The mission engineering method proposed by [56] includes a system definition, system model, and system analysis event sequence. There are several different approaches and uses for mission engineering in the literature, but all aim to ensure mission achievement with a holistic approach within the defined system of interest (SOI).

Emergent behaviors may affect a microgrid system's ability to support the electrical demands of different mission scenarios. Even with trained operational personnel and properly maintained equipment, the personnel cannot execute their mission functions if they lack the necessary power to support them. For instance, recently in Texas [57], consumers turned up their thermostats during cold weather while grid operators had to cut the amount of power distributed to prevent a months-long energy crisis. The major generation sources on the Texas grid suffered damages due to the extreme cold (causing many to shut down), while consumers were increasing their power demand to heat their homes and businesses during the storm. The power demand from consumers overwhelmed the grid's remaining power generation capacity, resulting in grid operators taking actions that included significant load shed to prevent cascading physical damage to the grid infrastructure [57]. This resulted in many facilities such as manufacturing lines losing power which disrupted production for days or even months.

If a military base's microgrid sheds a load, the mission capabilities that load supports will be limited or lost until the microgrid capability is fully recovered and the mission equipment is returned to service. If a military microgrid has a mission scenario with a critical load that requires more power than a degraded microgrid can provide, microgrid energy resilience is insufficient. This may result in critical loads being shed, loss of power throughout part or all the facility, and potentially an overall failed or compromised mission scenario that the microgrid is required to support. Due to the more dangerous nature of missions related to national defense, the outcome a of failed or compromised mission within a military base could range from loss of monetary value to loss of human life. With sufficient DERs in a microgrid, parallel reliability networks may exist to ensure vital equipment continues to receive power supplies, even in the event of individual component failures or damage [58]. In the event of a destructive scenario such as severe weather or adversary action, the microgrid system needs to minimize its vulnerability to cascading damage events while increasing the system recoverability to provide adequate power for mission needs of the military base [59]. Thus, it is important to understand the missions that a microgrid may be called upon to support to ensure the missions will receive uninterrupted power despite emergent events, severe weather, adversary action, and other such events.

\subsection{Related Research}

Several publications specifically related to military microgrid resilience are salient to this article [3-5,25,48,49,60-62]. Peterson et al. develop a method of analyzing the resilience of a military microgrid that can be used to conduct trade-off studies of alternative microgrid configurations [62]. Peterson et al.'s approach determines the power flow within the microgrid according to load demand DER and ESS capacity, and then models potential load shed scenarios all from a system-engineering perspective [3]. In Peterson et al.'s method, the loads are stochastic and time-dependent, and the microgrid's mission spans two weeks with hourly data fidelity. A Monte Carlo simulation allows random time-dependent failures of microgrid components, or the user may insert specific failure scenarios. Peterson et. al. define the mission and associated loads using MDI and assume that the mission impact is constant throughout a two-week grid outage. This fails to consider that different operational 
environments and missions may change a load's level of importance to national defense and its mission impact during islanded mode. Peterson et al.'s work is built upon and expanded in several further works including to estimate microgrid resilience life-cycle cost, improve resilience energy storage methods, in permanently islanded microgrid renewable energy applications, and nanogrid resilience applications [2,3,48,49,61].

Kain et al. build upon Peterson et al.'s work and present an analysis method to evaluate the resilience of military midrogrids that use a zonal shipboard power philosophy (also sometimes referred to as nanogrids) where each critical load or subset of critical loads can be isolated from the rest of the microgrid and run independently with local DERs and ESSs [2]. Giachetti et al. analyze the costs incurred by disruptions in energy supply and consider the trade space between a microgrid's resilience and cost [25]. Hildebrand analyzes the cost of improving military microgrid resilience by building upon Peterson et al.'s work [61]. Beaton expands Peterson et al.'s microgrid failure events to include many and man-made natural disasters and the geographic nature of such disasters [48]. Herster-Dudley develops an analysis of recovery actions based in part upon Peterson et al.'s failure scenarios [63]. Anuat et al. takes inspiration from Peterson et al. to analyze microgrid resilience from the perspective of the diesel fuel supply chain for military facilities [38]. Our work further extends Peterson et al. to analyze microgrid resilience from the perspective of changing operational requirements during a failure event.

Many publications focus on DOD energy strategy from the perspective of minimizing energy use and cost while recognizing the necessity of energy security. Most existing literature generally does not discuss how to define sufficient energy availability to meet operational needs. Strakos et al. discuss how DOD energy policy and research is organized into categories: energy research for reducing demand, expanding energy supplies, and building energy policy into the future force without a central mechanism to support strategic goals [64]. Hartranft focuses on US Army installation energy security, and recognizes that there is a diverse range of missions with scalable energy requirements [65]. Without defining how to account for variable missions, Hartranft advocates for microgrid architectures that allow a mission commander to make changes in prioritizing loads as missions evolve [65]. However, existing research does not include how the operational situation and different missions affect a DOD facility's energy requirements. Thus, a gap exists in the literature in understanding how unpredictable and rapidly changing missions a defense facility may perform can impact energy resilience.

\section{Methodology}

In this section, we introduce a system-engineering method to analyze the potential different mission scenarios a military facility may be called upon to perform from the perspective of changing loads and load prioritization. The method may be useful for other applications where mission needs can rapidly and unpredictably change; however, the method is developed specifically for military and national defense facilities. This method can be used to analyze either permanently islanded or grid-connected microgrids. The method's steps are graphically shown in Figure 2. The method is iterative and can study the various mission scenario load requirements and the hazards a microgrid may face to ensure all critical loads are served. If the critical loads are not sufficiently served, the microgrid design is then improved or altered through iteration of the design and the method is iterated until the microgrid is determined to be sufficiently resilient. 


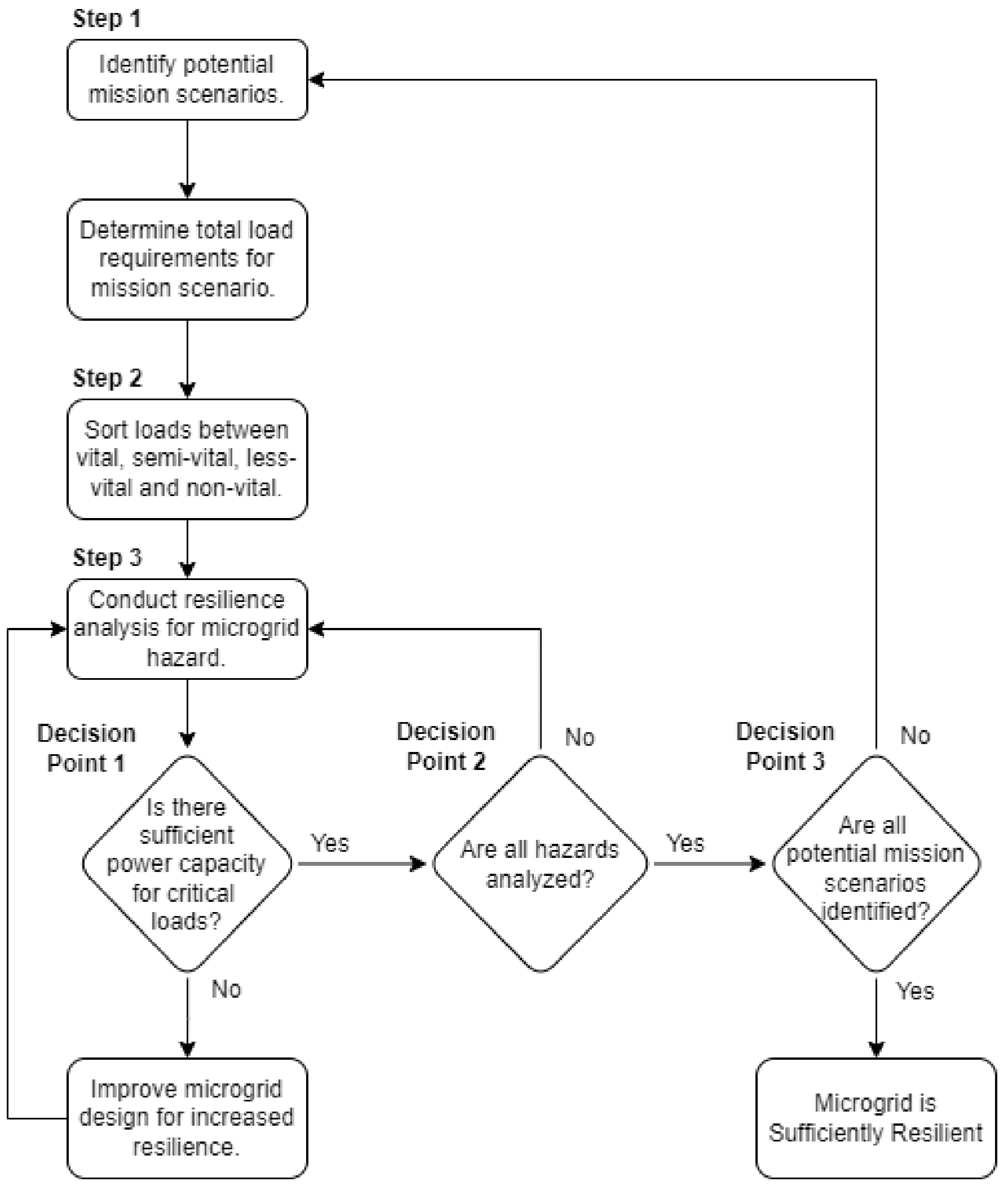

Analysis Complete

Figure 2. Method for Microgrid Resilience Load Planning and Verification. This flow chart may be followed by energy managers to ensure a designed or installed microgrid satisfies resilience requirements by identifying and modeling failure scenarios for all foreseen mission scenarios and their critical load supply needs. 


\subsection{Step 1: Identify Potential Different Mission Scenarios}

To determine potential different mission scenarios that a military base may be assigned that require electrical energy, first all permanent fixtures and ongoing missions on the military base need to be accounted for. We define permanent fixtures and missions as those structures and missions that do not easily move without major construction occurring. This includes, but is not limited to, the buildings and infrastructure that are held in place with concrete. The energy demanded from permanent fixtures and missions is the least changing variable, as any changes to these facilities involve planned construction over a given period. Next, the support infrastructure for deployable forces needs to be accounted for. The energy demand by deployable forces is variable depending on if the assets are located at the military base or deployed away from the base microgrid. This electrical demand is moderately variable depending on the capacity of the military base to host guest deployable forces (those that do not claim the location as their home port) and their required support. Deployable assets include equipment and personnel assigned aboard craft such as ships, aircraft, submarines, and vehicles that may require shore power services or maintenance support. Finally, the most variable energy need comes from personnel support. This includes the number of personnel on the base and the services requiring energy to support and provide for them. This may include, but not be limited to: medical support, food support, housing and hotel services, gym equipment operation, entertainment demands, personal transportation, and security demands. With an increased number of personnel present on the military base, there will be an increased number of energy demands from personnel support.

Additionally, any new equipment acquisitions or equipment updates affecting the future predicted energy demand on the military base must be accounted for to ensure the new expected electrical load(s) can be met. Large equipment updates and acquisitions are a slow process that will allow for energy planning prior to the installation of the equipment. For example, when the Navy Freedom and Independent Class Littoral Combat Ships (LCS) were being built, the training support infrastructure was in parallel developed and installed on the military bases that host those ships as their home ports [66]. Associated training loads such as ship operating simulators include large pieces of electronic equipment with an energy demand.

We propose accounting for all the potential mission scenarios that a base may be a part of, and their load demands, is depicted as shown in Figures 3 and 4, and described below. First, we consider mission scenarios that the baseline facility (the facility operating under normal conditions and mission scenarios but not considering any tenant commands) within the microgrid system boundary is capable of supporting. Next, each additional tenant command and other facilities that are supported within the microgrid system boundary is considered. On a military base, tenant commands have their own operational capabilities and equipment that draws power from the microgrid. The final consideration includes deployable assets. Deployable assets may include aircraft, ships, or submarines. Once the baseline facility, the additional tenant commands and facilities, and deployable assets are accounted for, mission scenarios may be generated from the combinations of potential operations conducted by each unit.

Following this, the energy demands of the identified loads associated with base missions-both ongoing and potential—need to be determined. One potential source of these data is historical data although base energy managers may need to estimate potential load data for missions that the base has not previously supported. Next, the loads must be sorted based upon their relative priority to one another to determine load shedding priority. 


\subsection{Step 2: Determine Critical Loads within the Mission Scenarios}

The determination of critical loads is subjective, as defined in the regulations and requirements discussed in Section 2.1. Our recommendation for the determination of critical loads on a military base is shown in Figure 5, which follows the findings in [10]. Our electrical power demand prioritization for mission-critical assessment includes four priority levels which have been adapted and modified from the three levels of the naval vessel load shedding criteria [45]. As listed below, these loads are sorted to conduct load adjudication and prioritization when the electrical supply fails to meet all electrical demands [11]. The times indicated within each prioritization level definition are estimated based upon the necessary response times to immediate threats to protect the military base, the necessary amount of time to launch the deployable assets, and initial repair times. The timeline intent for equipment use and load prioritization is estimated upon the needed usage immediacy for mission actions following a microgrid failure event. These timelines should be tailored as necessary to meet the intent of each prioritization level for a specific location, and are only supplied here as a reference baseline. Example missions for each priority level are shown in Figure 5 where the first mission priority (vital equipment) is the immediate defense of people and equipment necessary for national security. The last priority (nonvital equipment) are morale, welfare, and recreation (MWR) type missions with potentially longer acceptable recovery periods. These mission type priorities are examples, and should be tailored for each military base depending on operational stakeholder input. Once the loads have been grouped, our recommendation for critical loads used for microgrid resilience analysis include all loads in the vital, semi-vital, and less-vital priority categories with power supply adjudication following the priority indications in the event critical loads must be shed.

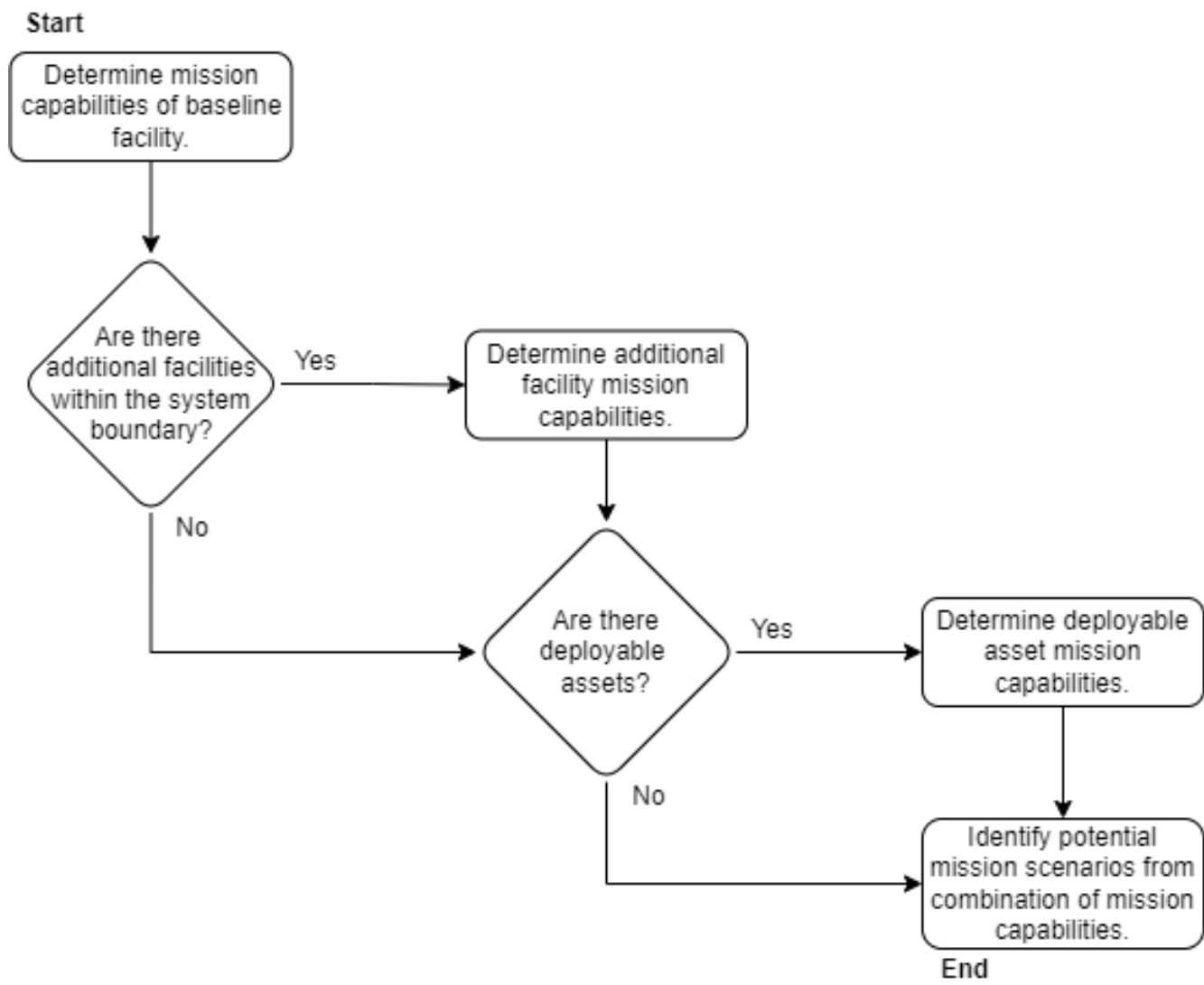

Figure 3. Identify Potential Capabilities. This flow chart adds detail to the first action in Step 1 of the methodology to ensure that all missions that the microgrid supplies are considered during the load analysis. 
Start

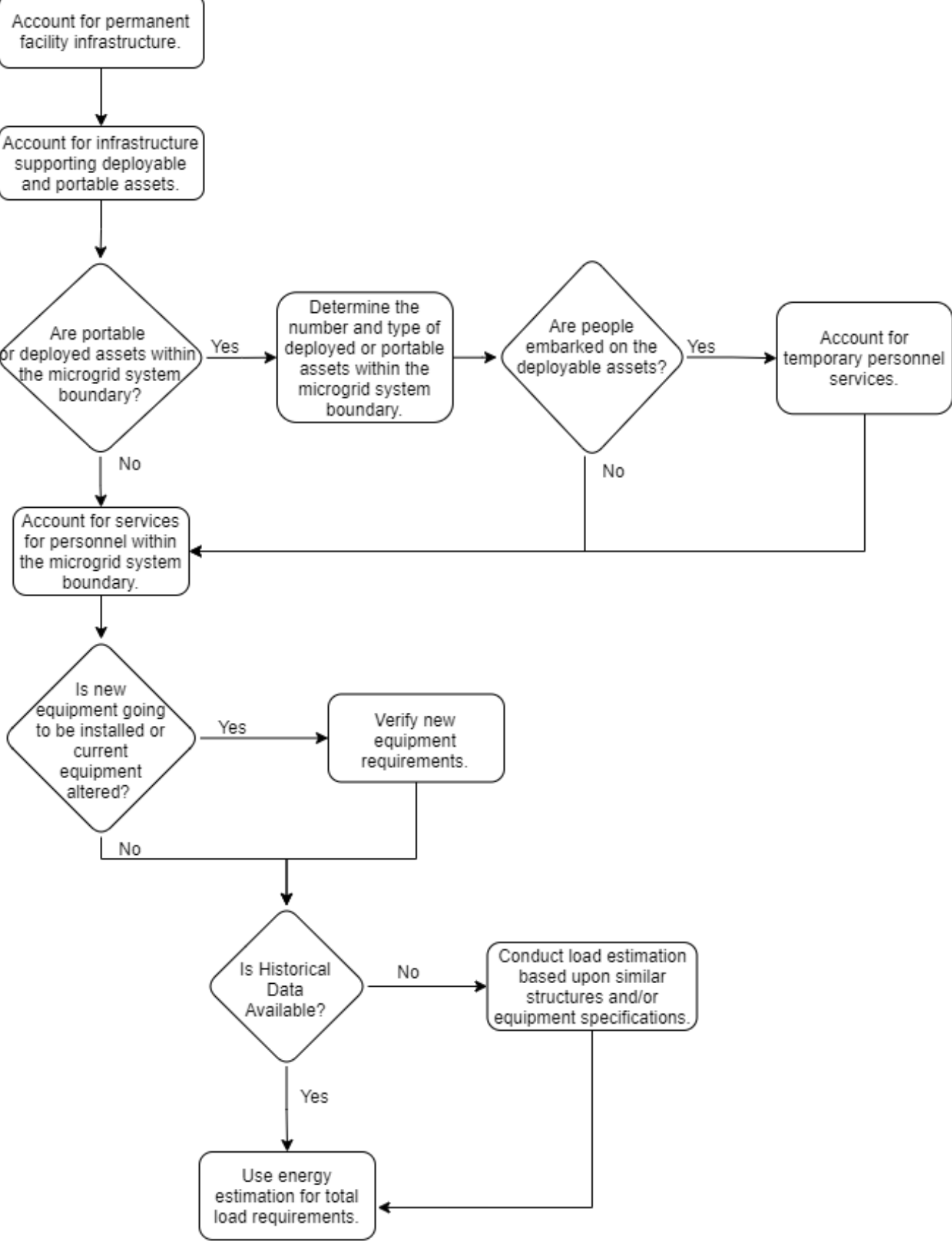

End

Figure 4. Determine Potential Load Demand. This flow chart adds detail to the second action in Step 1 of the methodology to ensure the load demands of all equipment supplied within the electrical boundary are considered. 


\section{Vital}

Intent: Defense of People and Physical Security

Examples: Hospital, Security, Firefighting, Defense Systems

\section{Semi-vital \\ Intent: Support for Deploying Forces}

Examples: Shore Power, Communications Equipment, Port Operations, Flight Control Towers, Cranes/Tractors for Weapons or Stores Onload

Less-vital
Intent: Maintenance of Equipment, Training for Personnel, and Hotel
Services
Examples: Simulators, RMC, Hotel/Housing, Galley, Commissary
Non-vital
Intent: Enabling of Moral, Welfare and Recreation
Examples: Gym, Movie Theater, Additional Restaurants, Shopping

Figure 5. Recommended Mission Priorities for Critical Load Determination. This figure shows what loads are considered vital, semi-vital, less vital, and non-vital.

1. Vital: Does this equipment affect the immediate defense and security of the installation against attack? If power is lost to this equipment for an extended period, could lives be lost or equipment important to national defense be destroyed? Examples include defense weapon systems, countermeasure systems, threat warning systems, medical operating rooms, security systems, and firefighting facilities. The timeline for the necessity of this equipment is measured in minutes to hours for immediate defense and lifesaving.

2. Semi-vital: Is this equipment necessary for mission accomplishment? Does this mission immediately affect national security? The timeline for the necessity of this equipment is measured within 6-72 h of immediate use. Examples include communications equipment, computer processing, cranes, aircraft tractors, equipment elevators and hanger bay doors. This equipment is used to coordinate, launch, and deploy assets.

3. Less vital: Is this equipment necessary for longer term recovery operations? Is this equipment necessary for long-term mission accomplishment? The timeline for this equipment is measured between days and weeks. Examples include the galley, sewer, water purification facilities, maintenance facilities, training facilities, and hotel services.

4. Non-vital: This includes all other electrical demand equipment that does not affect mission operations and the safety of equipment or personnel. The timeline for the necessity of this equipment is measured in months or longer. Examples include, but are not limited to laundry, scullery, gym equipment, entertainment equipment, and frivolous kitchen machines (vending machines, ice cream, popcorn, coffee, food court restaurants, etc.).

Depending on the predicted risk of a hazard (failure initiating event) to a base microgrid, actions may be taken to remove high value deployable assets. Each asset has a different timeline necessary to complete steps for safe deployment. Such actions may occur as a result of events such as weather sortie conditions [67] or changes in the Force Protection 
Conditions (FPCON). When ships are in port and conducting maintenance availabilities, they report to staff commands the time required to remove scaffolding and take other actions to deploy the craft. This information may be used to tailor the timeline estimations for equipment usage immediacy. The time required to launch naval aviation craft are often established through current Alert Postures, the requirements of which are established through the Naval Air Training and Operating Procedures Standardization Program (NATOPS) manuals and local squadron Standard Operating Procedures (SOP) [68]. Ships have underway checklists, with preparatory steps completed depending on the immediacy of the deployment [69]. Base energy managers should contact tenant commands to determine the specific timeline necessary to conduct procedures for emergency deployment.

\subsection{Step 3: Conduct Resilience Analysis}

Once potential mission scenario energy needs are identified in Step 1 and prioritized in Step 2, a resilience analysis can be conducted of the microgrid to verify that the installed or designed microgrid is resilient enough to provide power to critical missions in times of disrupted or degraded microgrid operations. To conduct this analysis, hazard and threat assumptions must be made. Our method does not focus on the probability of a specific hazard or failure impacting a microgrid, but rather analyzes the resilience of the microgrid to a variety of postulated failure scenarios. A microgrid energy manager can analyze mission scenarios, critical loads required to successfully execute mission scenarios, and the ability of the microgrid to meet energy demands throughout each specific threat or failure scenario. The threat or failure scenarios may be tailored as required to those possible threats anticipated by each individual location. The scenarios we include in this article serve as a starting point for practitioners, but we advise that practitioners carefully analyze their own facilities to determine all potential scenarios of interest.

We recommend including failure and threat scenarios such as microgrid faults due to weather phenomenon, equipment component failure, and loss of fuel supply. Weather and environmental phenomena such as fires, hurricanes, flooding, earthquakes, extreme hot and/or cold weather, can result in increase of electrical demand by users as well as microgrid component failure or degradation due to operating outside of the intended component specifications. Component failure in the microgrid may occur due to normal part reliability failure, accidental mishaps (e.g., plane crash, ship collision, or car crash), or malicious physical attacks (e.g., terrorist, active shooter, or insider threat equipment sabotage).

Once the failure or threat scenarios are determined, the microgrid is then modeled to assess its resilience in the face of each identified failure or threat scenario. In this article, we use the microgrid power flow model established in [3], tailoring the inputs with the appropriate energy load demands determined in Steps 1 and 2. However, a practitioner may choose to use a different microgrid resilience analysis method such as that proposed by Giachetti et al. [25] if desired. Regardless of which microgrid resilience analysis method is used by the practitioner, the resulting resilience analysis is used to understand different potential outcomes to the failure or threat scenarios to improve upon the microgrid design.

After a failure or threat scenario event occurs, the continued performance of the microgrid must meet or exceed the needs of mission-critical loads to minimize the impact to mission performance. This is graphically shown in Figure 1 where line four should remain above line three so that intersection points $\mathrm{A}$ and $\mathrm{B}$ never occur. Thus, the time period during which microgrid capability falls cannot support all critical loads is minimized.

\subsubsection{Decision Point 1}

At Decision Point 1 , each failure scenario is individually assessed to ensure the identified critical loads are served. If there is sufficient power capacity for all critical loads, then the next identified hazard is assessed. Otherwise, if analysis of a failure scenario indicates a critical load is not served for at least part of the facility mission duration, the microgrid should be improved and reassessed for the same hazard. In this case, our proposed method proceeds to microgrid design improvement and iterates back to Step 3 to conduct resilience 
analysis again. Once the improved microgrid has demonstrated sufficient power capacity for critical loads during a specific postulated failure scenario, the analysis continues with the next failure scenario until all scenarios have been demonstrated to successfully supply energy to critical loads. After this decision point is successfully passed, the proposed method proceeds to Decision Point 2.

\subsubsection{Decision Point 2}

Although all potential failure or hazard scenarios should have been identified and analyzed by Decision Point 2, we suggest that practitioners double-check that there are not any newly identified or emerging scenarios that should be included in the analysis. This decision point is intended to identify such overlooked scenarios and ensure they are analyzed. Once the microgrid has demonstrated its capability to supply critical loads for all failure or hazard scenarios including any newly identified scenarios, the process continues to the final decision point.

\subsubsection{Decision Point 3}

In Step 1, different combinations of mission scenarios are identified. Once the failure and hazard scenarios are assessed for one combination of mission scenarios, additional potential mission scenario combinations are analyzed. Once all mission scenario combinations are analyzed including scenarios with maximum electrical demands, and the analysis demonstrates that no load shed for critical electrical loads occurs for all identified failure and hazard scenarios, the microgrid is determined to be sufficiently resilient.

\section{Case Study}

In this section, we present a case study of a fictitious military base and microgrid to demonstrate the proposed method. The military base is intentionally fictitious to protect national security but is representative of a typical Naval base that many countries maintain around the world. The major elements of the fictitious military are shown in Figure 6, and include a pier, fire station, medical clinic, movie theater, fast food restaurant, gym, hotel, galley, five office buildings, and one large housing building. The permanent missions the base performs and associated facilities include the buildings and the pier itself. The deployable forces include any vessels that are moored to the pier, with the energy demand fluctuating based upon the number of ships connected to shore power. The possible number of ships that can connect via shore power should be considered to account for all deployable forces. This number is likely larger than the number of ships who are home ported at this base, and is limited by the length of the pier, the width of safe water along the pier (for nested vessels), and the number of shore power interfaces on the pier. The personnel support can be accounted for by determining the number of personnel billets (number of people) provided to each tenant command located on the base, the number of racks (places for sailors to sleep) available on the possible ships, and the number of hotel beds. The barracks housing is not added to the personnel total, because they are accounted for via the command billets and ship racks. Although this method of counting personnel is not perfect due to visitors potentially staying out in nearby towns and commuting to the base or ships nesting together along the pier to increase possible capacity, it is a reasonably close estimation of the energy demanded from personnel through services on the base. 


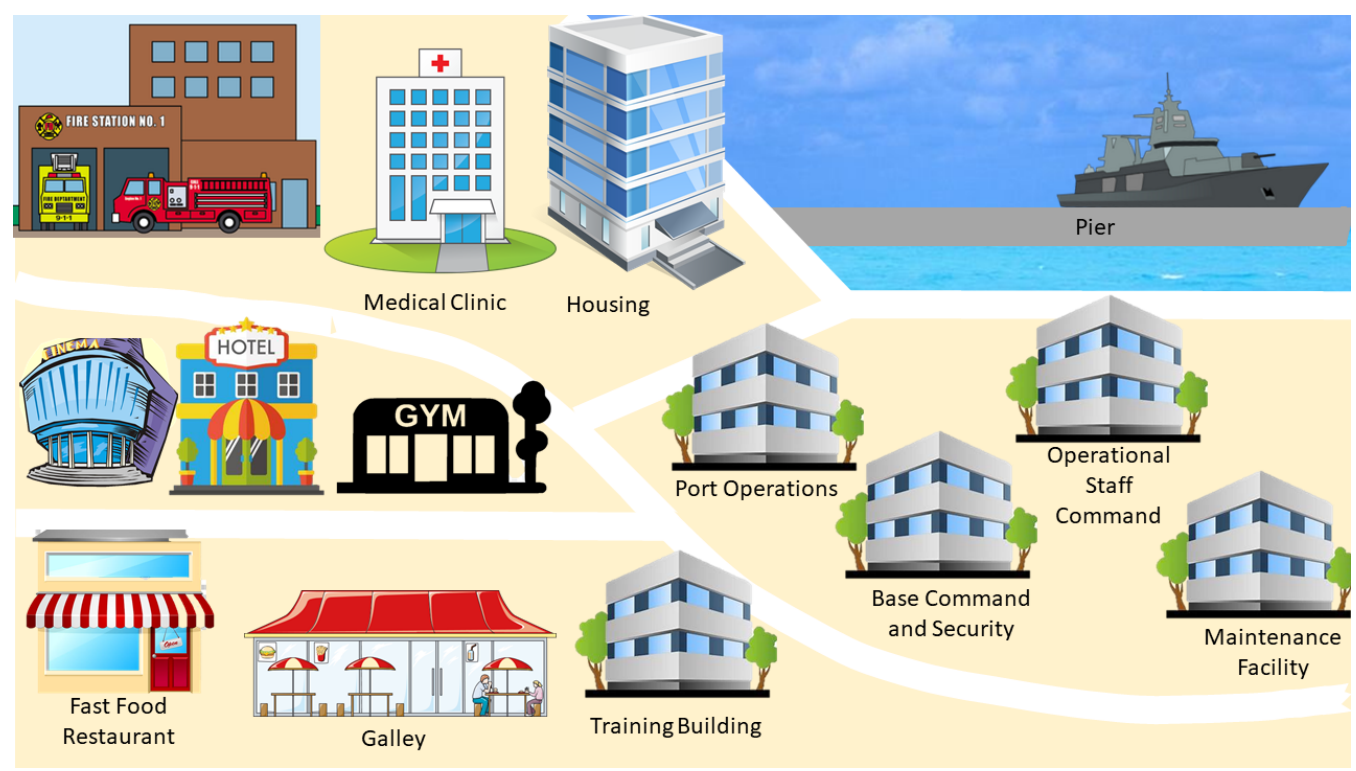

Figure 6. Fictitious Military Base Map. This image is used to demonstrate the possible mission combinations that may be determined.

The initial design of the microgrid includes a utility grid connection, four diesel generators with 2.5 MW capacity each, and a 90,000-gallon fuel storage supply split between the generators shown in Figure 7. This is an example of an installed microgrid with a power capacity chosen to meet historical load demands of the location, with realistic generators values as seen in Table 1. The fuel storage size was determined by fuel consumption over seven days, with refueling conducted to support continued generator operation during a prolonged grid outage. A resilience analysis of potential threats is then conducted using the identified mission capabilities of the location and the capability of the current microgrid composition. Following the discovery of critical loads being shed, iterative improvements of the microgrid are made with the addition of PV arrays and BESSs. Ideally, an assessment should be conducted for any location prior to microgrid installation, with early resilience and operational load demand analysis conducted to prevent additional time and costs spent building microgrid improvements. However, the reality is that many military bases now contain ad hoc microgrids.

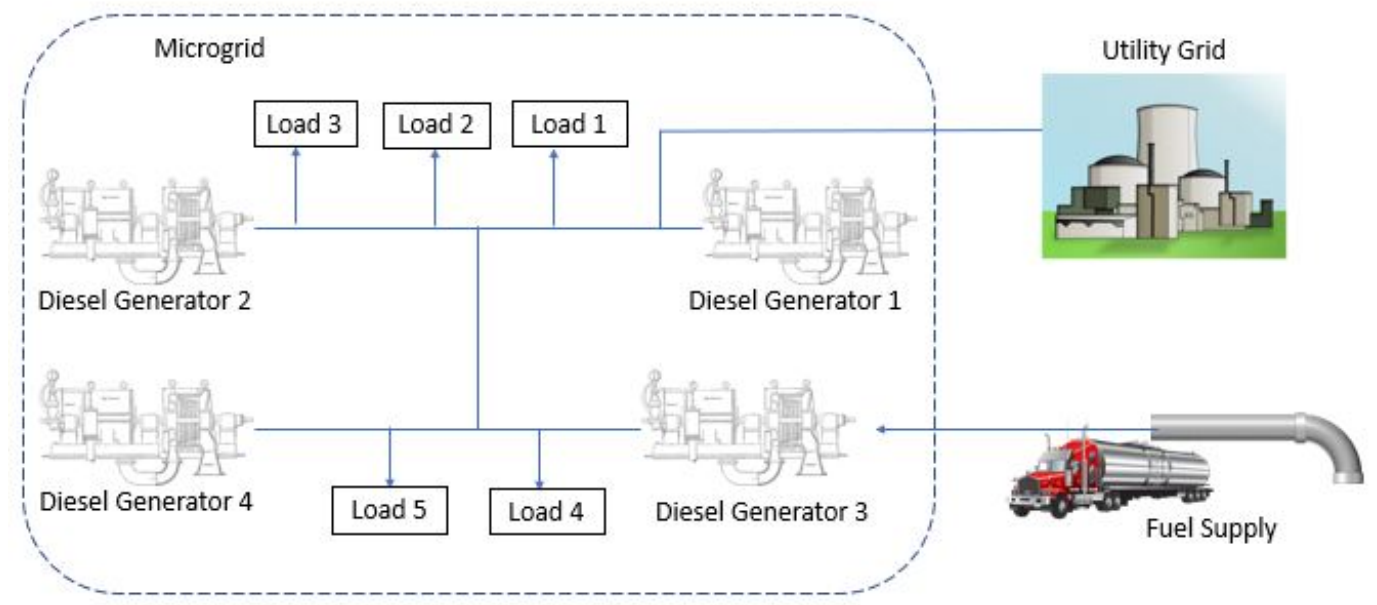

Figure 7. Initial Microgrid Composition. An initial microgrid design is developed based upon realistically installed equipment and initial energy load estimations. 


\subsection{Step 1: Identify Potential Mission Scenarios}

Following the proposed method described in the previous section, the mission capabilities are first identified for the base command. The base command's mission is administrative in nature, and therefore their capabilities include mostly communication. The additional facilities for this base include the medical clinic, fire station, barracks housing, port operations, operational staff commands, maintenance facilities, training command, galley, and MWR services. The deployable assets include the ships on the pier. The mission capabilities for each identified operational stakeholder are listed in Table 2. Potential mission scenarios the base may be required to support include any combination of the identified capabilities. Different tenant commands may have different mission priorities that coincide with one another. For instance, one ship may be undergoing maintenance, another ship may be conducting simulator training, while a third ship may be conducting regular underway movements for sea trial testing prior to deployment.

Table 2. Assumed Capabilities of Fictitious Base. The identified commands represent operational stakeholders with differing mission priorities. The mission capabilities are the possible missions for each stakeholder that the microgrid supplies.

\begin{tabular}{|c|c|}
\hline Command & Mission Capabilities \\
\hline Base Command & Administration and Communications \\
\hline Fire Station & Emergency Response \\
\hline Medical Clinic & Routine Healthcare and Emergency Response \\
\hline Barracks Housing & Hotel Services \\
\hline Movie Theater & Entertainment (MWR) \\
\hline Hotel & Hotel Services \\
\hline Gymnasium & Exercise (MWR) \\
\hline Fast Food Restaurant & Food Options (MWR) \\
\hline Galley & Provide Basic Sustenance \\
\hline Training Command & $\begin{array}{l}\text { Fleet Readiness: Inspections, } \\
\text { and Classroom Training }\end{array}$ \\
\hline Port Operations & Pilot, Tug, Security Operations \\
\hline Security & Emergency Response, Gate Security \\
\hline Operational Staff Command & Administration and Communications \\
\hline Maintenance Facility & $\begin{array}{l}\text { Equipment Maintenance, Overhaul, } \\
\text { Scaffolding, Crane Operations }\end{array}$ \\
\hline Ships & $\begin{array}{l}\text { Pier Work, Sea and Anchor Detail, Crane } \\
\text { Operations (on/off load), Refueling, Training, } \\
\text { Maintenance, Deployment }\end{array}$ \\
\hline
\end{tabular}

Once the potential missions a base may perform have been identified, it becomes necessary to determine the total load requirements for each mission scenario. A list is made for all the energy demands as described in the Section 3 above. Historical data may be used for analysis from usage reports of the facilities located on a base for each mission scenario. It is important to gather historical data that is represented of the mission scenario, no just general facility use. If this information is unavailable, estimated values from usage hours and specifications may be compared with historical data of similar structures. This case study uses the later option.

In this case study, we developed historical load data for each mission using data from similar structures collected in the DOE commercial reference buildings model [70]. To simulate high personnel capacity at the location, the largest consumption of electricity over a two-week period is used to account for load demand for each applicable building 
type. We suggest taking this approach when real historical data are not available for a specific mission to prevent underestimating the potential load. When the deployed forces are out to sea and not connected to the microgrid, the minimal personnel usage is estimated with the smallest two-week electrical consumption for each applicable structure type, and is used for operational electrical load demand variability comparison. For load demands not available in the DOE model, we used publicly disclosed point values to generate synthetic load data [71-73].

\section{Mission Scenarios}

For this case study, the first mission scenario focuses solely on the permanent and ongoing missions but not including deployed forces or temporary support. This mission scenario occurs while all ships are deployed. The second mission scenario includes the first mission scenario plus the addition of the deployed assets that have come back to the base. Three vessels are pierside in various operational phases: one ship conducting training, one ship conducting scheduled maintenance, and one ship conducting short underway movements in preparation for deployment. A fourth ship is included in this mission scenario when it returns to port following a severe mishap such as a collision with another ship or battle damage and must undergo unplanned corrective maintenance. Hospital operations, galley output, and lodging are all increased to maximum capacity due to additional ships and supporting personnel at the location. All ships are connected to shore power. This section includes operational critical load graphs for the two different mission scenarios described above and shown in Figure 8.

\section{Operational Impact to Electrical Demand}

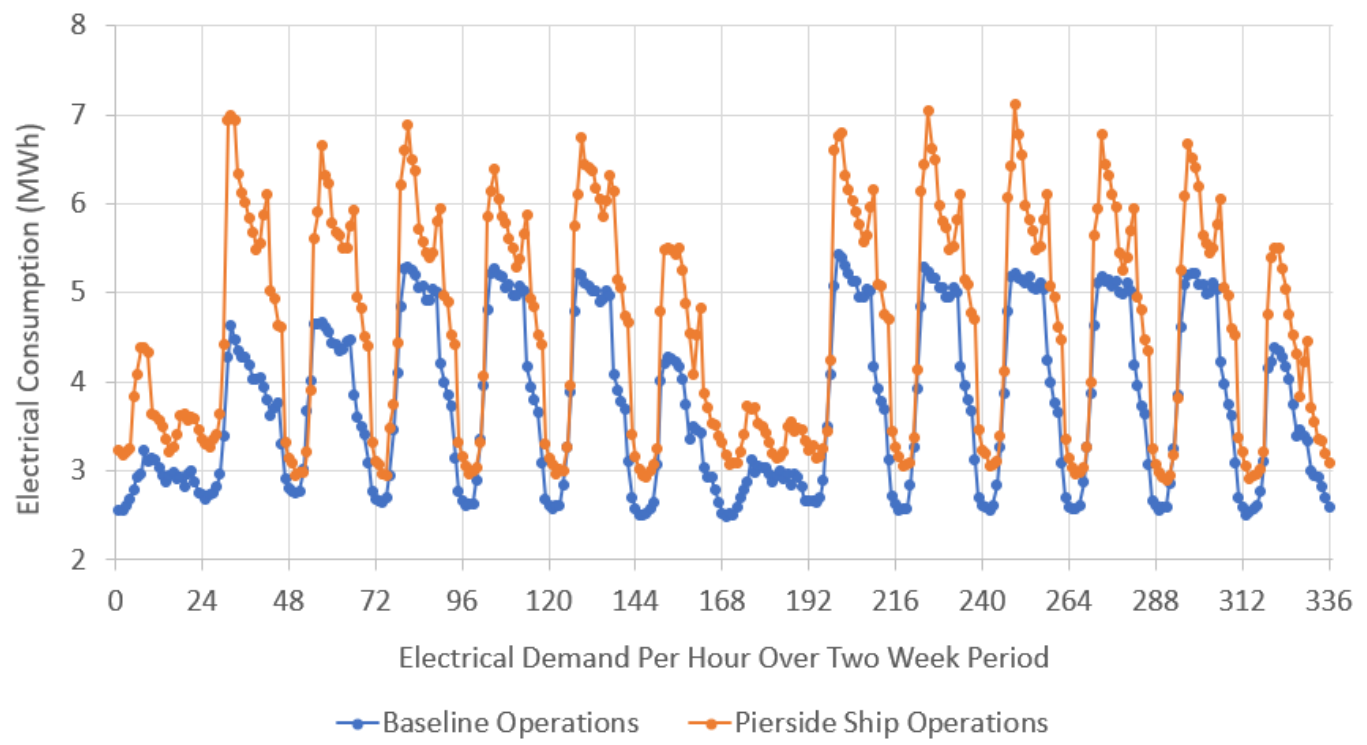

Figure 8. Identified Potential Mission Scenarios and Their Critical Load Demands. This graph shows the effect that the considered operational mission scenario has on the microgrid functional requirement to meet critical load demands within the system boundary. To ensure successful mission execution, higher operational mission load combinations must be verified to satisfy resilience standards.

\subsection{Application of Step 2: Determine Critical Loads within the Mission Scenarios}

Once all the potential mission loads have been identified, they must be sorted between vital, semi-vital, less vital, and non-vital. This ensures that the highest priority loads are continuously fed electrical power, and the lower priority loads have power when available, and are otherwise shed based on priority and available power. In this case study, prioritized loads follow those identified in Figure 5, and are detailed in Table 3. 
Table 3. Organization of Critical Loads within Microgrid System by Priority Level. This table shows how the identified critical loads are organized in the model to ensure any required load shed occurs in order of determined priority.

\begin{tabular}{ccccc}
\hline Load 1 & Load 2 & Load 3 & Load 4 & Load 5 \\
\hline Fire Station & Pier & Maintenance & Base Command & Galley \\
Medical Clinic & Port Operations & Training & Staff & Housing \\
& & & & Hotel \\
\hline
\end{tabular}

\subsection{Application of Step 3: Conduct Resilience Analysis}

In this case study, a resilience analysis was conducted using the microgrid power flow model established in [3]. The load demand input was identified in Step 1 for two mission scenarios, and sorted into electrical load shed priorities in Step 2. The failure and hazard scenarios used in the analysis are specifically chosen by the base energy manager to represent worst-case scenarios for the microgrid because a microgrid with resilience to highly damaging scenarios is assumed to be more resilient to a wide range of unanticipated failure and hazard scenarios. The worst-case scenarios ensure that in emergent scenarios the critical loads at the base will have sufficient energy supply to ensure mission success.

The resilience analysis is first run with no failure or hazard scenarios to verify the current microgrid system meets predicted critical loads in both mission scenarios. Next, the specific failure and hazard scenarios are analyzed and include component failure, excessively hot weather, and loss of fuel supply. A component failure scenario is tested to represent malicious physical attack by an adversary such as shooting a substation transformer, an accidental incident such as a car hitting a power pole, and a reliability failure such as the loss of one diesel generator. In the excessive heat scenario, there is potential for failures due to overheating generators and PV efficiency degradation. The weather failure scenario was tested for a loss of one diesel generator and PV efficiency to decrease by four percent. In the event that the fuel supply chain is interrupted, the microgrid continues to operate with the fuel currently stored available until the fuel supply is exhausted. With no available fuel to refill the diesel tanks, the microgrid continues to operate using other forms of installed DER and BESS.

\subsubsection{Decision Point 1}

Although the initial microgrid system was sufficient to meet critical energy demands for both mission scenarios, it failed to meet all critical loads when failures were modeled. Therefore, iterative changes were made to improve the microgrid until no critical loads were shed in the model for the current analyzed failure.

\subsubsection{Decision Point 2}

Each of the three identified hazards was independently assessed against the most recent microgrid design in the first mission scenario being tested. If the microgrid was improved in the previous hazard, the improved design was tested against the new hazard within the mission scenario until the microgrid demonstrated sufficient resilience for all hazards within the mission scenario.

\subsubsection{Decision Point 3}

After the first mission scenario is demonstrated to be supported with a resilient microgrid in all three identified hazards, the second mission scenario is analyzed and verified with the most recent improved microgrid design. The second mission scenario has different critical load inputs for the model as determined in Steps 1 and 2 previously, but is analyzed with the same failure and hazard scenarios. Following verification that the final microgrid design satisfies resilience requirements for all three hazards in both mission scenarios, the microgrid design is determined to be sufficiently resilient. 


\subsection{Summary of Findings}

The first failure scenario analyzed was component failure during the mission scenario with the ships are out to sea and no deployable craft are connected to the microgrid. With the original microgrid design shown in Figure 7, the power generation capacity was found to be insufficient, resulting in critical loads shed for a total of 15 out of $336 \mathrm{~h}$ analyzed. This is equivalent to $15 \mathrm{~h}$ between points A and B on the System Resilience Curve shown in Figure 1. The microgrid design was then improved to include the addition of one $10,000 \mathrm{~m}^{2}$ PV array at $18 \%$ efficiency and one BESS with 5 MWh capacity with charge and discharge rate of $300 \mathrm{~kW} / \mathrm{h}$, and reanalyzed with the same failure scenario. With this microgrid design, no loads were shed due to microgrid component failure in the first mission scenario. The next failure scenario analyzed is the weather phenomenon of excessive heat in the mission scenario with the ships out to sea, where the improved microgrid design resulted in no loads shed.

The final hazard scenario assessed was the loss of fuel supply, which failed the resilience analysis with loads shed over 39 out of 336 analyzed hours. The microgrid was then improved to the final design shown in Figure 9 of four $2.5 \mathrm{MW}$ diesel generators, five $9600 \mathrm{~m}^{2}$ PV arrays at 18\% efficiency, and five BESS with 50 MWh capacity with charge and discharge rate of $1600 \mathrm{~kW} / \mathrm{h}$. Despite increasing the capacity of the BESS may be costly, it remains within the characteristics of lead-acid electrochemical energy storage technologies used in grids [43] while each PV array size approximates three football fields. Although this seems to be a large area, use of PV array placement on covered parking areas and building rooftops may result in feasible space for installation. After the final microgrid design satisfied resilience requirements in the first mission scenario, it was then verified against the increased critical load demands of the second mission scenario.

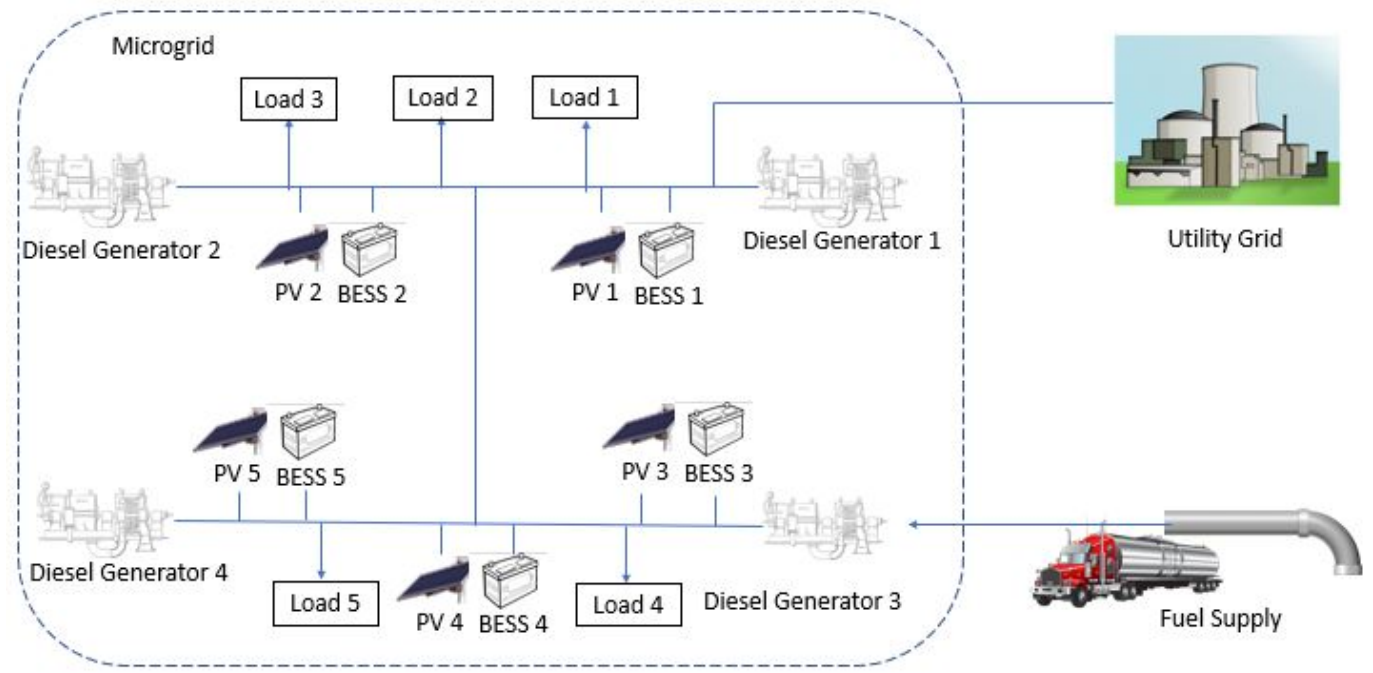

Figure 9. Final Microgrid Composition. This image displays the final microgrid composition, which includes four 2.5 MW diesel generators, five $9600 \mathrm{~m}^{2} \mathrm{PV}$ arrays at $18 \%$ efficiency, and five BESS with $50 \mathrm{MWh}$ capacity with charge and discharge rate of $1600 \mathrm{~kW} / \mathrm{h}$.

The results of the load shed hours for all three microgrid designs in all three hazard scenarios, for both mission scenarios are summarized for comparison and discussion in Table 4. As shown, the final microgrid design results in a satisfactorily resilient microgrid with no critical loads shed across all assessed hazard scenarios. 
Table 4. Summary of Load Shed Analysis Results. This table includes the data for all three identified hazards analyzed with the different microgrid iterative designs, mission scenarios, and the resulting critical load shed hours.

\begin{tabular}{|c|c|c|c|}
\hline Mission Scenario & Failure Scenario & Microgrid Composition & $\begin{array}{l}\text { Load Shed Hours } \\
\text { (Load 1/2/3/4/5) }\end{array}$ \\
\hline \multirow{3}{*}{$\begin{array}{l}\text { No deployable assets, ships } \\
\text { out to sea }\end{array}$} & \multirow{3}{*}{ Component Failure } & Four 2.5 MW Diesel Generators & $5 / 9 / 9 / 9 / 15$ \\
\hline & & $\begin{array}{c}\text { Four 2.5 MW Diesel Generators, } \\
\text { 10,000 } \mathrm{m}^{2} \mathrm{PV}, 5 \text { MWh BESS }\end{array}$ & 0 \\
\hline & & $\begin{array}{c}\text { Four 2.5 MW Diesel Generators, Five } \\
9600 \mathrm{~m}^{2} \mathrm{PV} \text {, Five } 50 \mathrm{MWh} \text { BESS }\end{array}$ & 0 \\
\hline \multirow{3}{*}{$\begin{array}{l}\text { No deployable assets, ships } \\
\text { out to sea }\end{array}$} & \multirow{3}{*}{ Weather Phenomenon } & Four 2.5 MW Diesel Generators & 0 \\
\hline & & $\begin{array}{c}\text { Four 2.5 MW Diesel Generators, } \\
\text { 10,000 } \mathrm{m}^{2} \mathrm{PV}, 5 \mathrm{MWh} \text { BESS }\end{array}$ & 0 \\
\hline & & $\begin{array}{l}\text { Four 2.5 MW Diesel Generators, Five } \\
9600 \mathrm{~m}^{2} \mathrm{PV} \text {, Five } 50 \mathrm{MWh} \text { BESS }\end{array}$ & 0 \\
\hline \multirow{3}{*}{$\begin{array}{l}\text { No deployable assets, ships } \\
\text { out to sea }\end{array}$} & \multirow{3}{*}{ Loss of Fuel Supply } & Four 2.5 MW Diesel Generators & $81 / 81 / 81 / 81 / 81$ \\
\hline & & $\begin{array}{c}\text { Four 2.5 MW Diesel Generators, } \\
\text { 10,000 } \mathrm{m}^{2} \mathrm{PV}, 5 \text { MWh BESS }\end{array}$ & $39 / 39 / 39 / 39 / 39$ \\
\hline & & $\begin{array}{c}\text { Four 2.5 MW Diesel Generators, Five } \\
9600 \mathrm{~m}^{2} \mathrm{PV} \text {, Five } 50 \mathrm{MWh} \text { BESS }\end{array}$ & 0 \\
\hline \multirow{3}{*}{ Ships In Port } & \multirow{3}{*}{ Component Failure } & Four 2.5 MW Diesel Generators & $22 / 36 / 40 / 28 / 40$ \\
\hline & & $\begin{array}{l}\text { Four 2.5 MW Diesel Generators, } \\
\text { 10,000 m² PV, } 5 \text { MWh BESS }\end{array}$ & $30 / 31 / 31 / 30 / 35$ \\
\hline & & $\begin{array}{l}\text { Four 2.5 MW Diesel Generators, Five } \\
9600 \mathrm{~m}^{2} \mathrm{PV} \text {, Five } 50 \text { MWh BESS }\end{array}$ & 0 \\
\hline \multirow{3}{*}{ Ships In Port } & \multirow{3}{*}{ Weather Phenomenon } & Four 2.5 MW Diesel Generators & $38 / 38 / 38 / 38 / 38$ \\
\hline & & $\begin{array}{c}\text { Four 2.5 MW Diesel Generators, } \\
\text { 10,000 m² PV, } 5 \text { MWh BESS }\end{array}$ & $12 / 25 / 25 / 17 / 28$ \\
\hline & & $\begin{array}{l}\text { Four 2.5 MW Diesel Generators, Five } \\
9600 \mathrm{~m}^{2} \mathrm{PV} \text {, Five } 50 \text { MWh BESS }\end{array}$ & 0 \\
\hline \multirow{3}{*}{ Ships In Port } & \multirow{3}{*}{ Loss of Fuel Supply } & Four 2.5 MW Diesel Generators & $136 / 136 / 136 / 136 / 136$ \\
\hline & & $\begin{array}{c}\text { Four 2.5 MW Diesel Generators, } \\
\text { 10,000 } \mathrm{m}^{2} \mathrm{PV}, 5 \mathrm{MWh} \text { BESS }\end{array}$ & $110 / 110 / 110 / 110 / 110$ \\
\hline & & $\begin{array}{l}\text { Four 2.5 MW Diesel Generators, Five } \\
9600 \mathrm{~m}^{2} \mathrm{PV} \text {, Five } 50 \mathrm{MWh} \text { BESS }\end{array}$ & 0 \\
\hline
\end{tabular}

Comparing the load shed results directly between mission scenarios, it is readily apparent that the ships in port had higher electrical loads. For the ships in port mission scenario, load shed occurred for longer durations and for more failure scenarios. If fuel loss had not been considered, it would have been easy to assess that only a small PV and single BESS addition would have been sufficient while the ships were underway. Considering the loss of the diesel generation capability focuses electrical resiliency on renewable resources, causing a significant improvement upon the original design of only diesel generation. This early significant improvement was able to cover the additional critical load demand of the ships connected to microgrid shore power.

Interesting trends shown in the data include much longer load shed times for loss of fuel supply than any other hazard. To satisfy load demands following loss of fuel, a large increase in microgrid capacity PV and BESS solutions was required to entirely compensate for the loss of diesel generation. Although the addition of the single PV array and BESS was not enough to ensure a fully resilient solution, it did provide an additional $26 \mathrm{~h}$ of critical 
load operation. This would increase the amount of time allotted to energy managers to find and have delivered an alternate fuel source solution to recover the microgrid without suffering load shed to critical equipment, and resulting loss of mission accomplishment.

Additionally, when load shed occurs, the entire microgrid goes offline for periods of time, causing all critical loads to be shed. This indicates that an increased number of smaller, dispersed DER may be the more resilient solution with a higher redundancy due to spare parts and higher resilience due to being dispersed. Even if the total generation capability is the same, the loss of one DER would have a smaller effect on microgrid resilience.

\section{Discussion and Future Work}

One benefit of using microgrids to improve energy resilience of defense facilities is maintaining power for critical loads while faults occur at one or more power sources among the DER and/or while the microgrid is disconnected from the grid. For instance, in the case study a failure scenario removed capability temporarily from one of the DERs but the system was able to manage the load until recovery was completed.

Military bases have different mission priorities and requirements at different times. The power a base microgrid may be called upon to provide for support to each state of readiness or operational tasking will vary, affecting the microgrid's resilience level. Lower electrical demand requirements mean the designed microgrid DER has additional redundancy and increased resilience. Higher power requirements during certain mission scenarios may result in little to no redundancy in the DER and decreased resilience. Ships, aircraft, submarines, vehicles, or people may deploy to or from a military base, which then must meet the changing mission needs and resulting loads. The baseline mission load for a military base includes the power demand from permanent missions while variable mission load demands from missions that are not always being conducted at the base need to be considered and accounted for.

The case study analysis is limited in the number of failure and hazard scenarios, and mission scenarios assessed, as it is only an example application of the proposed methodology. The case study is also limited with the use of assumed and generated historical data instead of actual values, and did not use rightsizing optimization techniques when improving the microgrid. Additionally, life-cycle costs where not a consideration in the case study but are recognized as a hindrance to improving microgrids. Without budgeted funds, energy managers may still analyze their system to ensure operational stakeholders are aware of the risks and limitations of the installed microgrid resilience system in the face of failure and hazard scenarios. Using the proposed methodology to conduct analysis and identify potential gaps in microgrid resilience in support of mission execution with accompanying proposed solutions may be useful in pursuing funds for microgrid improvement efforts.

From our experience, cost (and especially economics) is the primary driving factor in most microgrid development cycles for military applications. Unless at least one dollar of savings can be shown under normal operating conditions, a microgrid project to improve resilience will not be funded. Although there are efforts underway with some defense organizations to change the situation, cost is still the primary driving factor. Other work exists that specifically addresses the cost of resilience (e.g., $[25,61])$. In short: increasing resilience in a military microgrid almost always costs more money than it could save. Thus, we have explicitly not addressed cost in this article. Future work includes identifying the lowest cost options to improve resilience.

The proposed method introduced above provides a system-engineering perspective on energy resilience for defense installation microgrids with changing operational requirements. The recommendation to add additional renewable generation sources can cause issues that are generally identified during detailed electrical engineering analyses. A variety of methods exist in the literature to analyze potential electrical engineering issues associated with introducing renewables to microgrids [74-78]. Future work could include linking the proposed method with existing electrical engineering methods. 
Microgrids at many defense installations already have or will soon be provided with renewable generation resources. The majority of installations we have personally inspected primarily focus on PV as a renewable energy generation source. Although not yet common, BESS are starting to be deployed to store energy and smooth out renewable generation during periods of low power production (e.g., cloudy days, nighttime, etc.). We expect to see significant growth in renewable energy generation (primarily PV) and BESS across many defense installations over the next decade.

Future work may include a more detailed study on the effects of fuel supply interruption for microgrid resilience. Installed diesel generators are used in most microgrid designs. With the loss of fuel, those DER become ineffective and result in not only a loss of invested acquisition funds, but also the inability to complete the mission in the event of disconnection from the utility grid.

\section{Conclusions}

This article presents a system-engineering method to analyze the impact on energy resilience of missions that a facility may be required to undertake on short notice due a changing operational environment. The proposed method provides the ability to determine what the critical load requirements are and analyze the ability of a microgrids to supply sufficient energy during hazard and failure scenarios affecting the microgrid. The proposed method will allow energy managers to assess and prepare for changing missions before potential load shed occurs which can prevent failed mission execution due to lack of electricity to critical equipment.

Varied missions result in varied electrical load demands. An example case study was conducted with a fictitious representative military base microgrid. By determining the mission capabilities of the operational stakeholders (the tenant commands) whose equipment interfaces with the microgrid, mission scenarios may be generated to account for potential electrical load demands. The identification of critical loads ensures microgrids may be installed or updated to ensure satisfactory resilience before load shedding occurs. Any load shed of critical equipment negatively impacts the operational stakeholder's mission execution. Careful determination of critical loads enables the development and implementation of resilient microgrids without having unnecessary costs due to oversizing the microgrid capacity. The addition of renewable energy resources, such as PV arrays and BESS, increases resilience to ensure mission execution during microgrid failure scenarios.

Author Contributions: Conceptualization, J.M., D.L.V.B. and A.P.; methodology, J.M., D.L.V.B. and A.P.; software, J.M.; validation, J.M., D.L.V.B. and A.P.; formal analysis, J.M., D.L.V.B. and A.P.; investigation, J.M., D.L.V.B. and A.P.; resources, D.L.V.B. and A.P.; data curation, D.L.V.B. and A.P.; writing — original draft preparation, J.M.; writing—review and editing, J.M., D.L.V.B. and A.P.; visualization, J.M.; supervision, D.L.V.B. and A.P.; project administration, D.L.V.B.; funding acquisition, D.L.V.B. and A.P. All authors have read and agreed to the published version of the manuscript.

Funding: This research received no external funding.

Institutional Review Board Statement: Not applicable.

Informed Consent Statement: Not applicable.

Data Availability Statement: Data and software are available upon request from the authors.

Acknowledgments: Any opinions or findings of this work are the responsibility of the authors, and do not necessarily reflect the views of the Department of Defense or any other organizations. Approved for Public Release; distribution is unlimited.

Conflicts of Interest: The authors declare no conflict of interest. 


\section{References}

1. Armed Forces: General Military Law Part I: Organization and General Military Powers: Chapter 1 Definitions. 10 U.S.C $\S 101(e)$. Available online: https://www.govinfo.gov/content/pkg/USCODE-2020-title10/pdf/USCODE-2020-title10-subtitleA-partIchap1-sec101.pdf (accessed on 10 October 2021).

2. Kain, A.; Van Bossuyt, D.L.; Pollman, A. Investigation of Nanogrids for Improved Navy Installation Energy Resilience. Appl. Sci. 2021, 11, 4298. [CrossRef]

3. Peterson, C.J.; Van Bossuyt, D.L.; Giachetti, R.; Oriti, G. Analyzing Mission Impact of Military Installations Microgrid for Resilience. J. Syst. Eng. 2021, 9, 69. [CrossRef]

4. Giachetti, R.E.; Peterson, C.J.; Van Bossuyt, D.L.; Parker, G.W. Systems Engineering Issues in Microgrids for Military Installations. INCOSE Int. Symp. 2020, 30, 731-746. [CrossRef]

5. Siritoglou, P.; Oriti, G.; Van Bossuyt, D.L. Distributed Energy-Resource Design Method to Improve Energy Security in Critical Facilities. Energies 2021, 14, 2773. [CrossRef]

6. Perl, R.; O'Rourke, R. Terrorist Attack on USS Cole: Background and Issues for Congress; Technical Report; Congressional Reporting Service, Library of Congress: Washington, DC, USA, 2001.

7. Chief of Naval Operations: Memorandum with Enclosures' Report on the Collision between USS FITZGERALD (DDG 62) and Motor Vessel ACX CRYSTAL' and 'Report on the Collision between USS JOHN S MCCAIN (DDG 56) and Motor Vessel ALNIC MC'; Technical Report; Office of the Chief of Naval Operations: Washington, DC, USA, 2017.

8. Clement, G.J.; Endrejat, F.; Price, J.; Sadighi, N. Critical Process Loads: Defining and Incorporating Them Into a Reliable Power System. IEEE Ind. Appl. Mag. 2019, 25, 38-48. [CrossRef]

9. Installation Energy Management; DOD Instruction 4170.11; Department of Defense: Washington, DC, USA, 2018.

10. Urban, A.; Zhivov, A.; Srivastava, A.; Keysar, E.; Thompson, C.; Judd, K.; Case, M. Energy Master Planning for Resilient Public Communities-Best Practices from US Military Installations. ASHRAE Trans. 2020, 126, 828-848.

11. Lord, E.M. Metrics and Standards for Energy Resilience at Military Installations; Official Memorandum, Department of Defense: Washington, DC, USA, 2020.

12. Bajwa, A.A.; Mokhlis, H.; Mekhilef, S.; Mubin, M. Enhancing power system resilience leveraging microgrids: A review. J. Renew. Sustain. Energy 2019, 11, 035503. [CrossRef]

13. Bruneau, M.; Chang, S.E.; Eguchi, R.T.; Lee, G.C.; O’Rourke, T.D.; Reinhorn, A.M.; Shinozuka, M.; Tierney, K.; Wallace, W.A.; von Winterfeldt, D. A Framework to Quantitatively Assess and Enhance the Seismic Resilience of Communities. Earthq. Spectra 2003, 19, 733-752. [CrossRef]

14. Schneider, K.P.; Tuffner, F.K.; Elizondo, M.A.; Liu, C.C.; Xu, Y.; Ton, D. Evaluating the Feasibility to Use Microgrids as a Resiliency Resource. IEEE Trans. Smart Grid 2017, 8, 10.

15. Krishnamurthy, V.; Kwasinski, A. Effects of Power Electronics, Energy Storage, Power Distribution Architecture, and Lifeline Dependencies on Microgrid Resiliency During Extreme Events. IEEE J. Emerg. Sel. Top. Power Electron. 2016, 4, 1310-1323. [CrossRef]

16. Ton, D.T.; Smith, M.A. The U.S. Department of Energy's Microgrid Initiative. Electr. J. 2012, 25, 84-94. [CrossRef]

17. Feng, W.; Jin, M.; Liu, X. A review of microgrid development in the United States-A decade of progress on policies, demonstrations, controls, and software tools. Appl. Energy 2018, 228, 1656-1668. [CrossRef]

18. Tuffner, F.K.; Schneider, K.P.; Hansen, J.; Elizondo, M.A. Modeling Load Dynamics to Support Resiliency-Based Operations in Low-Inertia Microgrids. IEEE Trans. Smart Grid 2019, 10, 2726-2737. [CrossRef]

19. Van Broekhoven, S.; Judson, N.; Galvin, J.; Marqusee, J. Leading the Charge: Microgrids for Domestic Military Installations. IEEE Power Energy Mag. 2013, 11, 40-45. [CrossRef]

20. Eddy, J.; Miner, N.E.; Stamp, J. Sandia's Microgrid Design Toolkit. Electr. J. 2017, 30, 62-67. [CrossRef]

21. Hussain, A.; Bui, V.H.; Kim, H.M. Microgrids as a resilience resource and strategies used by microgrids for enhancing resilience. Appl. Energy 2019, 240, 56-72. [CrossRef]

22. Mishra, S.; Anderson, K.; Miller, B.; Boyer, K.; Warren, A. Microgrid resilience: A holistic approach for assessing threats, identifying vulnerabilities, and designing corresponding mitigation strategies. Appl. Energy 2020, 264, 114726. [CrossRef]

23. Jiang, P.; Huang, S.; Zhang, T. Asymmetric Information in Military Microgrid Confrontations-Evaluation Metric and Influence Analysis. Energies 2020, 13, 1954. [CrossRef]

24. Lenhart, S.; Araújo, K. Microgrid decision-making by public power utilities in the United States: A critical assessment of adoption and technological profiles. Renew. Sustain. Energy Rev. 2021, 139, 110692. [CrossRef]

25. Giachetti, R.E.; Van Bossuyt, D.L.; Anderson, W.; Oriti, G. Resilience and Cost Trade Space for Microgrids on Islands. IEEE Syst. J. 2021, 1-11. [CrossRef]

26. Lee, E.K.; Shi, W.; Gadh, R.; Kim, W. Design and Implementation of a Microgrid Energy Management System. Sustainability 2016, 8, 1143. [CrossRef]

27. Kroposki, B.; Lasseter, R.; Ise, T.; Morozumi, S.; Papathanassiou, S.; Hatziargyriou, N. Making microgrids work. IEEE Power Energy Mag. 2008, 6, 40-53. [CrossRef]

28. Kliem, J.; McGinn, D. Ingredients for a Microgrid at U.S. Department of Defense Installations [Technology Leaders]. IEEE Electrif. Mag. 2020, 8, 6-120. [CrossRef] 
29. Office of the Assistant Secretary of Defense for Sustainment. Department of Defense Annual Energy Management and Resilience Report (AEMRR) Fiscal Year 2019; Office of the Assistant Secretary of Defense for Sustainment: Washington, DC, USA, 2020. Available online: https://www.acq.osd.mil/eie/ie/FEP_Energy_Reports.html (accessed on 15 September 2021).

30. Dempsey, M.; Putnam, E. A Practical Overview of Microgrids. International District Energy Association. 2014. Available online: https:/ / www.districtenergy.org/HigherLogic/System/DownloadDocumentFile.ashx?DocumentFileKey=56d51345-b7 fe-0c5a-0dd5-e4a6516ec77d\&forceDialog=0 (accessed on 7 August 2021).

31. Monohan, R. Experiences with Energy Planning for DOD Installations-Energy Projects at USMC Installations. International District Energy Association. 2017. Available online: https://www.districtenergy.org/viewdocument/experiences-with-energyplanning-fo-2 (accessed on 23 July 2021).

32. Benson, K. Experiences with Energy Planning for DOD Installations-Energy Projects at Navy Installations. International District Energy Association. 2017. Available online: https://www.districtenergy.org/viewdocument/experiences-with-energy-planningfo-1 (accessed on 17 July 2021).

33. Marine Corps Air Station Miramar Microgrid: From Design and Construction to Operations and Commissioning. Black \& Veatch. Available online: https://www.bv.com/projects/marine-corps-air-station-miramar-microgrid-design-and-constructionoperations-and (accessed on 9 November 2021).

34. Howland, E. Noresco Lands Contract to Expand Navy Microgrid under \$83.1M ESPC. Microgrid Knowledge. 2020. Available online: https:/ / microgridknowledge.com/noresco-navy-microgrid-connecticut/ (accessed on 2 March 2020).

35. Icari, M. NAVFAC Southwest Awards $\$ 7.8$ Million to Expand Twentynine Palms Microgrid. Naval Facilities Engineering Systems Command. 2017. Available online: https://www.navfac.navy.mil/news/2017_press_releases/october2017-press-releases/ navfac-southwest-awards7point8m-to-expand-twentynine-palms-microgrid.html (accessed on 17 October 2017).

36. Anderson, W.; Kobold, K.; Yakimenko, O. Tools for Analysis and Optimization of Standalone Green Microgrids. Int. J. Energy Power Eng. 2018, 12, 8.

37. Wilkie, C. Colonial Pipeline Paid 5 Million Ransom One Day after Cyberattack. CEO Tells Senate. CNBC. 2021. Available online: https:/ / www.cnbc.com/2021/06/08/colonial-pipeline-ceo-testifies-on-first-hours-of-ransomware-attack.html (accessed on 8 June 2021).

38. Anuat, E.; Van Bossuyt, D.L.; Pollman, A. Energy Resilience Impact of Supply Chain Network Disruption to Military Microgrids. Infrastructures 2022, 7, 4. [CrossRef]

39. Reich, D.; Oriti, G. Rightsizing the Design of a Hybrid Microgrid. Energies 2021, 14, 4273. [CrossRef]

40. Mohanned, Y.S.; Maruf, A.A.; Thomas, S.; Koyunlu, G.; Usman, U.; Adeshina, S.A. A Synopsis for Utilization of Energy Storage Systems in Distributed Power Generation. In Proceedings of the 2019 IEEE PES/IAS PowerAfrica, Abuja, Nigeria, 20-23 August 2019; pp. 204-208.

41. Aming, D.; Rajapakse, A.; Molinski, T.; Innes, E. A technique for evaluating the reliability improvement due to energy storage systems. In Proceedings of the 2007 Canadian Conference on Electrical and Computer Engineering, Vancouver, BC, Canada, 22-26 April 2007; pp. 413-416.

42. Hussain, A.; Bui, V.H.; Kim, H.M. A Proactive and Survivability-Constrained Operation Strategy for Enhancing Resilience of Microgrids Using Energy Storage System. IEEE Access 2018, 6, 75495-75507. [CrossRef]

43. Faisal, M.; Hannan, M.A.; Ker, P.J.; Hussain, A.; Mansor, M.B.; Blaabjerg, F. Review of Energy Storage System Technologies in Microgrid Applications: Issues and Challenges. IEEE Access 2018, 6, 35143-35164. [CrossRef]

44. Rosales-Asensio, E.; de Simón-Martín, M.; Borge-Diez, D.; Blanes-Peiró, J.J.; Colmenar-Santos, A. Microgrids with energy storage systems as a means to increase power resilience: An application to office buildings. Energy 2019, 172, 1005-1015. [CrossRef]

45. Naval Sea Systems Command. Electrical Power Distribution Systems, Naval Ships' Technical Manual Chapter 320 Revision 2; Naval Sea Systems Command: Washington, DC, USA, 1998. Available online: https://fas.org/man/dod-101/sys/ship/nstm/ch320.pdf (accessed on 17 July 2021).

46. Das, L.; Munikoti, S.; Natarajan, B.; Srinivasan, B. Measuring smart grid resilience: Methods, challenges and opportunities. Renew. Sustain. Energy Rev. 2020, 130, 109918. [CrossRef]

47. Kujawski, E.; Miller, G. The Mission Dependency Index: Fallacies and Misuses. INCOSE Int. Symp. 2009, 19, 1565-1580. [CrossRef]

48. Beaton, D.T. Testing Whether Distributed Energy Storage Results in Greater Resilience of Microgrids. Master's Thesis, Naval Postgraduate School, Monterey, CA, USA, 2021.

49. Anderson, W. Resilience Assessment of Islanded Renewable Energy Microgrids. Ph.D. Thesis, Department of Systems Engineering, NPS, Monterey, CA, USA, 2020.

50. Antelman, A.; Dempsey, J.J.; Brodt, B. Mission Dependency Index-A Metric for Determining Infrastructure Criticality. In Infrastructure Reporting and Asset Management: Best Practices and Opportunities; American Society of Civil Engineers: Reston, VA, USA, 2008; pp. 141-146.

51. Hernandez, A.S.; Karimova, T.; Nelson, D.H.; Ng, E.; Nepal, B.; Schott, E. Mission engineering and analysis: Innovations in the military decision making process. In Proceedings of the American Society for Engineering Management (ASEM) 2017 International Annual Conference: Reimagining Systems Engineering and Management, Tuscaloosa, AL, USA, 18-21 October 2017; pp. 521-530. 
52. Magnus, S.H. Mission Engineering Guide; Office of the under Secretary of Defense for Research and Engineering: Washington, DC, USA, 2020

53. Hutchison, N.; Miller, W.; Yan See Tao, H.; Verma, D.; Vesonder, G. Framework for Mission Engineering Competencies. In Proceedings of the 28th Annual INCOSE International Symposium, Washington, DC, USA, 7-12 July 2018.

54. Poza, A.S. Mission Engineering. Int. J. Syst. Syst. Eng. 2015, 6, 161. [CrossRef]

55. Hernandez, A.S.; Hatch, W.D.; Pollman, A.G.; Upton, S.C. Computer experimentation and scenario methodologies to support integration and operations phases of mission engineering and analysis. In Proceedings of the 2018 Winter Simulation Conference (WSC), Gothenburg, Sweden, 9-12 December 2018; pp. 3765-3776.

56. Van Bossuyt, D.L.; Beery, P.; O'Halloran, B.M.; Hernandez, A.; Paulo, E. The Naval Postgraduate School's Department of Systems Engineering Approach to Mission Engineering Education through Capstone Projects. Systems 2019, 7, 38. [CrossRef]

57. Douglas, E. Texas Was 'Seconds and Minutes' away from Catastrophic Months Long Blackouts, Officials Say. Texas Tribune. 2021. Available online: https:/ / www.texastribune.org/2021/02/18/texas-power-outages-ercot/ (accessed on 8 June 2021).

58. Blanchard, B.; Fabrycky, W. Systems Engineering and Analysis, 5th ed.; Prentice Hall: Boston, MA, USA, 2011.

59. Richards, M.G.; Hastings, D.E.; Ross, A.M.; Rhodes, D.H. 7.1. 1 Survivability design principles for enhanced concept generation and evaluation. INCOSE Int. Symp. 2009, 19, 1055-1070. [CrossRef]

60. Siritoglou, P. Distributed Energy Storage Design and Modeling to Improve the Energy Security of Naval Facilities. Master's Thesis, Naval Postgraduate School, Monterey, CA, USA, 2019.

61. Hildebrand, J.P. Estimating the Life Cycle Cost of Microgrid Resilience. Master's Thesis, Naval Postgraduate School, Monterey, CA, USA, 2020.

62. Peterson, C.J. Systems Architecture Design and Validation Methods for Microgrid Systems. Master's Thesis, Naval Postgraduate School, Monterey, CA, USA, 2020.

63. Herster-Dudley, M.R. Building Resilience within DOD Microgrids by Considering Human Factors in Recovery Procedures. Master's Thesis, Naval Postgraduate School, Monterey, CA, USA, 2021.

64. Strakos, J.K.; Quintanilla, J.A.; Huscroft, J.R. Department of Defense energy policy and research: A framework to support strategy. Energy Policy 2016, 92, 83-91. [CrossRef]

65. Hartranft, T.J. Energy Security and Independence for Military Installations: Candidate Mission-Focused Vision and Policy Measures. In Proceedings of the ASME 2007 Energy Sustainability Conference, Long Beach, CA, USA, 27-30 June 2007. [CrossRef]

66. NAVSEA News. Fleet Supports LCS Crew Proficiency Through Virtual Reality Training. 2017. Available online: https://www. navsea.navy.mil/Media/News/Article/1303834/fleet-supports-lcs-crew-proficiency-through-virtual-reality-training/ (accessed on 8 September 2017).

67. U.S. 4th Fleet Public Affairs. Sortie Condition Alpha Set in Mayport; Ships Get Underway as Hurricane Dorian Approaches. Military News, 3 September 2019. Available online: https://www.militarynews.com/news/sortie-condition-alpha-setin-mayport-ships-get-underway-as-hurricane-dorian-approaches/article_5094ec2a-ce5e-11e9-a3f8-5f94c687ec2e.html\#: : text $\%$ E7\% $\% 6 \%$ ADortie $\% 20$ Conditions $\% 20$ are $\% 20$ as $\% 20$ (accessed on 3 September 2019).

68. NATOPS General Flight and Operating Instructions Manual; COMNAVAIRFOR M-3710.7; Department of the Navy: San Diego, CA, USA, 2016.

69. Surface Ship Navigation Department Organization and Regulations Manual; COMNAVSURFPAC/COMNAVAIRPAC/COMNAVAIRLANT /COMNAVSURFLANTINST 3530.4F; Department of the Navy: San Diego, CA, USA, 2018

70. Deru, M.; Field, K.; Studer, D.; Benne, K.; Griffith, B.; Torcellini, P.; Liu, B.; Halverson, M.; Winiarski, D.; Rosenberg, M.; et al. U.S Department of Energy Commercial Reference Building Models of the National Building Stock; Technical Report; NREL: Golden, CO, USA, 2011.

71. Eastern Research Group; Energy \& Environmental Research Associates. Shore Power Technology Assessment at U.S. Ports; Technical Report; United States Environmental Protection Agency, Office of Transportation and Air Quality: Washington, DC, USA, 2017.

72. US Energy Information Administration. Commercial Buildings Energy Consumption Survey (CBECS) Table PBA4. Electricity Consumption Totals and Conditional Intensities by Building Activity Subcategories, 2012; US Energy Information Administration: Washington, DC, USA, 2016. Available online: https://www.eia.gov/consumption/commercial/data/2012/c\&e/cfm/pba4.php (accessed on 16 November 2021).

73. Liebherr. LTM 1300-6.2-Powerful with an Innovative Drive Concept. Available online: https://www.liebherr.com/en/usa/ products/mobile-and-crawler-cranes/mobile-cranes/liebherr-mobile-cranes/ltm-1300-6.2.html (accessed on 16 November 2021).

74. Alhelou, H.H.; Golshan, M.H.; Askari-Marnani, J. Robust sensor fault detection and isolation scheme for interconnected smart power systems in presence of RER and EVs using unknown input observer. Int. J. Electr. Power Energy Syst. 2018, 99, 682-694. [CrossRef]

75. Alhelou, H.H.; Golshan, M.E.H.; Hatziargyriou, N.D. Deterministic dynamic state estimation-based optimal lfc for interconnected power systems using unknown input observer. IEEE Trans. Smart Grid 2019, 11, 1582-1592. [CrossRef]

76. Alhelou, H.H.; Golshan, M.E.H.; Hatziargyriou, N.D. A decentralized functional observer based optimal LFC considering unknown inputs, uncertainties, and cyber-attacks. IEEE Trans. Power Syst. 2019, 34, 4408-4417. [CrossRef] 
77. Alhelou, H.A.H.; Cuffe, P. A Dynamic State Estimator Based Tolerance Control Method Against Cyberattack and Erroneous Measured Data for Power Systems. IEEE Trans. Ind. Inform. 2021. [CrossRef]

78. Haesalhelou, H.; Parthasarathy, H.; Nagpal, N.; Agarwal, V.; Nagpal, H.; Siano, P. Decentralised Stochastic Disturbance ObserverBased Optimal Frequency Control Method for Interconnected Power Systems with High Renewable Shares. IEEE Trans. Ind. Inform. 2021, 18, 3180-3192. [CrossRef] 